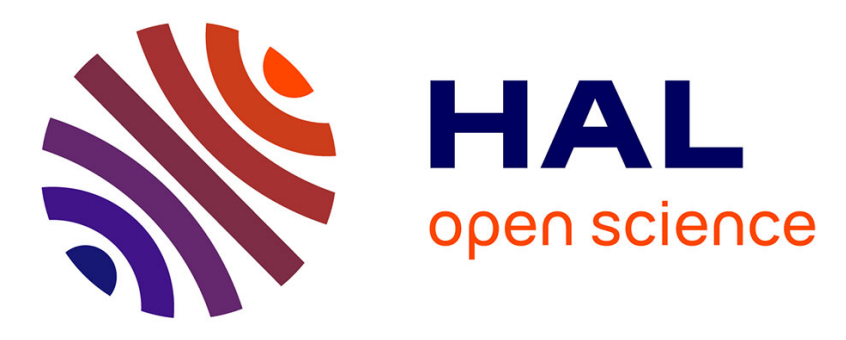

\title{
Adaptive Output Feedback Control of Interleaved Parallel Boost Converters Associated with Fuel Cell
}

Boualem Salhi, Hassan El Fadil, Tarek Ahmed-Ali, Eric Magarotto, Fouad Giri

\section{- To cite this version:}

Boualem Salhi, Hassan El Fadil, Tarek Ahmed-Ali, Eric Magarotto, Fouad Giri. Adaptive Output Feedback Control of Interleaved Parallel Boost Converters Associated with Fuel Cell. Electric Power Components and Systems, 2015, Renewable Energy Devices and Systems - Research Frede Blaabjerg, 43 (8-10), pp.1141-1158. 10.1080/15325008.2014.995280 . hal-01151687

\section{HAL Id: hal-01151687 \\ https://hal.science/hal-01151687}

Submitted on 28 Jul 2021

HAL is a multi-disciplinary open access archive for the deposit and dissemination of scientific research documents, whether they are published or not. The documents may come from teaching and research institutions in France or abroad, or from public or private research centers.
L'archive ouverte pluridisciplinaire HAL, est destinée au dépôt et à la diffusion de documents scientifiques de niveau recherche, publiés ou non, émanant des établissements d'enseignement et de recherche français ou étrangers, des laboratoires publics ou privés.

\section{(c)(1)}

Distributed under a Creative Commons Attribution| 4.0 International License 


\title{
Adaptive Output Feedback Control of Interleaved Parallel Boost Converters Associated with Fuel Cell
}

\author{
Boualem Salhi, ${ }^{1}$ Hassan El Fadil, ${ }^{2}$ Tarek Ahmed Ali, ${ }^{3}$ Eric Magarotto, ${ }^{3}$ \\ and Fouad Giri ${ }^{3}$ \\ ${ }^{1}$ University of Mouloud Mammeri, Automatic Department, Tizi-Ouzou, Algeria \\ ${ }^{2}$ ENSA (Ecole Nationale des Sciences Appliquées), Genie des Systemes Lab, University Ibn Tofail, Kenitra, Morocco \\ ${ }^{3}$ University of Caen Basse-Normandie, GREYC Lab, Team Automatic Control, Caen, France
}

\begin{abstract}
This article addresses the problem of controlling DC-DC interleaved boost converters associated to fuel cell energy generators. The fuel cell-interleaved boost converter association powers a possibly unknown and time-varying resistance load; furthermore, interleaved boost converter parallel cells are not equipped with current sensors. The control objective is twofold: (1) the interleaved boost converter output voltage must be tightly regulated and (2) the total current carried by the interleaved boost converter must be equally shared between the different parallel branches. The complexity of the control problem lies in (i) the system non-linearity and instability of system zero dynamics with respect to output voltage, (ii) load uncertainty, and (iii) inaccessibility to measurements of all currents. The instability of the output voltage zero dynamics is addressed by reformulating all control objectives in terms of current regulation in the different converter cells. The resulting current regulation problem is dealt with by developing an adaptive output feedback controller including a collection of adaptive current regulators and estimators. Parameter adaptation is used for compensation of load uncertainty. It is shown that the proposed output feedback adaptive controller meets its objectives. This theoretical analysis is confirmed by numerical simulations and experimental tests showing additional robustness features.
\end{abstract}

Keywords: fuel cell, interleaved converter, boost power converter, adaptive control, output feedback control

\section{INTRODUCTION}

Among renewable energies, hydrogen and fuel cells (FCs) are considered promising alternatives from both energy storage and supply reliability viewpoints. Indeed, these sources not only feature a high-efficiency chemical-energy conversion (into electrical energy) but also feature low emissions [1-3]. The FC generators can produce electric energy directly from hydrogen and oxygen. The DC voltage generated by FCs is generally low amplitude, and it is not constant, depending on the operating conditions. Furthermore, FC systems have a dynamic response that is slower than the transient responses typically requested by the load. For this reason, in many applications, FC generators must be interfaced with other energy/ power sources by means of an electronic power converter 


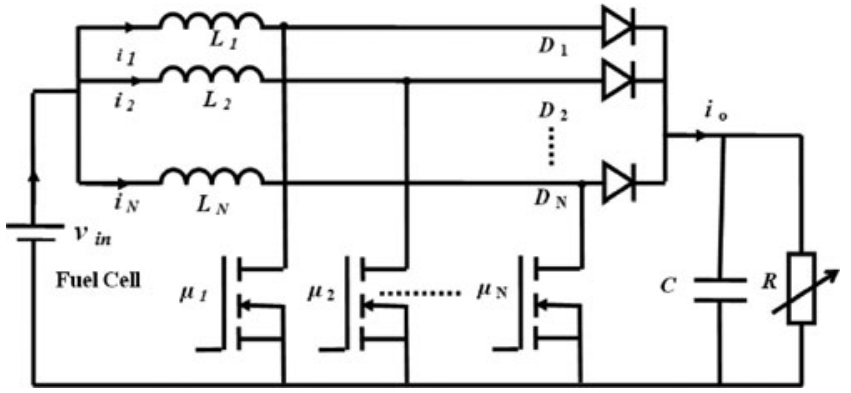

FIGURE 1. FC-IBC system.

[4-6]. Among the various topologies of DC-DC converters, the interleaved converter has been proposed as a suitable interface for FCs to convert low-voltage high-current input into a high-voltage low-current output [7-15]. The advantages of the interleaved boost converter (IBC) compared to the classical boost converter are low input current ripple, high efficiency, faster transient response, reduced electromagnetic emission, and improved reliability. IBCs are composed of a number of quasi-autonomous converters, called cells, paralleled all together to create a single large converter (Figure 1). According to the interleaving technique [7], the total current carried by the IBC is shared between the different cells, making possible size reduction of individual inductances and conduction power loss reduction in power components [8]. Another benefit of the interleaving technique is waveform ripple reduction due to harmonic cancelation between the different cells $[9,13]$.

The problem of controlling IBCs has been considered in different contexts depending on the desired objectives and the powering source nature. In [10], IBCs and parallel Cuk converters, powered by AC sources, were controlled to meet power factor correction. In [11], IBCs powered with photovoltaic (PV) cells have been controlled to meet the maximum power point tracking (MPPT) requirement. IBC topologies for use in high-performance FC systems have received increasing interest in recent years; see, e.g., [16-20]. It has been demonstrated both by simulations and experiments that IBCs are more competitive (than other DC/DC converter topologies) in achieving higher current ripple reduction, power efficiency, and reliability. They also enjoy better device ratings, and the total inductance volume and weight are decreased. A common point in previous works is the negligence of the nonlinearity of the controlled systems (including FCs and IBCs) in the control design. Generally, IBCs are described with linearized small-signal models, and linear proportional integral (PI) controllers are used. It is only recently that a non-linear control based solution has been proposed [13, 14]. In [13], the FC-IBC association is described by its large-signal nonlinear model, and a sliding-mode controller is designed on the basis of this model to meet a tight regulation of the IBC output voltage and equal current sharing between the IBC modules. The achievement of these control objectives has been demonstrated by simulation. In [14], the problem of DC-link stabilization for $\mathrm{FC} /$ supercapacitor hybrid power plants has been studied. Two controllers, including a linear PI and a non-linear flatness based, are designed on the basis of reduced-order models (of the FC converter and supercapacitor converter) and compared using simulation and experimental tests. However, the equal current sharing purpose is not considered.

A common limitation in all previous works is that all states were supposed to be accessible to measurements, and in some cases, the load was also assumed to be known and time invariant. The large number of the IBC cells makes it not economically effective to implement current sensors on each converter branch. Indeed, in addition to the sensor's implementation cost, the control system reliability turns out to be dependent on the number of implemented sensors. The larger the number of involved sensors is, the shorter the mean time before failure (MTBF) is. Therefore, it is of practical interest to use state estimators (instead of physical sensors) whenever this is possible. Finally, except for [13], no rigorous theoretical analysis has been made in previous works proving the closed-loop control system stability and control objective achievement. As a matter of fact, closed-loop theoretical analyses and experimental evaluations are complementary means to prove the efficiency of control solutions.

In this article, the focus is made on boost converters, involving $N$ parallel cells coupled to FC generators. The latter are electrochemical devices converting chemical energy into electricity. A typical non-linear voltage/current characteristic of an FC generator is illustrated by Figure 2. Presently, the FC-IBC association is powering a load resistance that is not supposed to be known a priori. The control objective is to tightly regulate the IBC output voltage and ensure a perfect sharing of the total current between the $N$ IBC cells. The output voltage is the only variable that is supposed to be accessible to measurements. The inductor current in each branch is not measured. Therefore, the control design includes a current estimator providing online estimates of all individual cell currents. On the other hand, when considering the load voltage as the output of boost-type converters, the resulting zero dynamics are unstable (i.e., the boost converters dynamics are non-minimum phase). This is addressed by reformulating the initial load-voltage regulation objective in terms of current regulation, exploiting the fact that the zero dynamics corresponding to each individual cell are stable. A current regulator is designed for each cell based on the current (estimator) equations. All regulators are fed with the same reference signal, the value of which is computed using power balance considerations. It turns out that the 


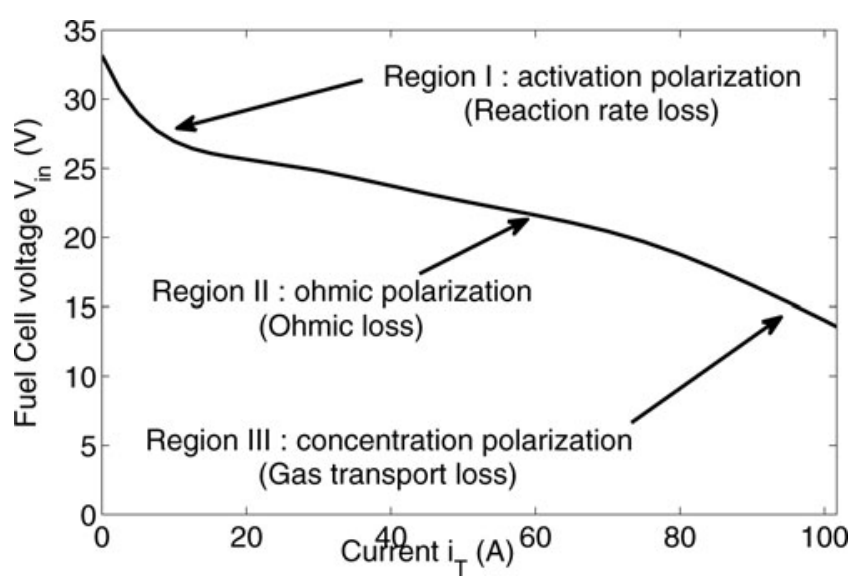

FIGURE 2. V-I characteristic of Ballard 1020A FC stack (Ballard Power Systems Inc., Burnaby, British Columbia, Canada).

reference value is a function of the load resistance, which is not known a priori and may be changing. This is coped with by designing a parameter adaptive law providing online estimates of the load. The adaptive controller thus obtained is referred to as output feedback because it only requires online measurements of the output voltage. Interestingly, the performance analysis of the controller is performed considering a single Lyapunov function accounting for all errors (current estimation errors, parameter adaptation error, and current tracking errors). It is formally shown that the controller does meet its control objectives. This theoretical result is further confirmed by numerical simulations and by experimental tests.

In the light of the above exposé, it is seen that the present controller enjoys the following features.

a. It is non-linear because it is designed on the basis of an accurate non-linear model, whereas most previous works have proposed linear controllers, e.g., [16-20].

b. It is made adaptive to cope with the uncertainty that prevails on the load resistance, unlike most previous works where this load was supposed to be constant and well known, e.g., [14, 16-20].

c. It is current sensorless because it does not need the measurements of the currents in the various parallel converters. To this end, a current estimator is designed that provides the control law with online estimates of the currents. The sensorless feature improves the controller reliability compared to previously proposed controllers where current measurements are supposed to be available $[13,14,16-20]$.

d. It is backed by a rigorous theoretical stability analysis formally demonstrating the achievement of the various control objectives, i.e., PV power MPPT, IBC out- put voltage regulation, equal current sharing between parallel converters, and unit power factor at the IBC-grid connection.

This article is organized as follows. Section 2 is devoted to the modeling of the IBC-FC association; controller design and analysis are performed in Section 3. Controller performances are further illustrated by numerical simulations in Section 4 . Experimental results are presented in Section 5.

\section{FC-IBC SYSTEM MODELING}

\subsection{Description of FC-IBC System}

The system under study (Figure 1) is an association of an FC and an IBC. The latter consists of $N$ identical boost converters (also referred to cells) paralleled to form one high-power highcurrent converter. These $N$ converters share the total current $i_{T}$ supplied by the FC generator. By using interleaved pulse width modulation (PWM) technique, each converter carries a current with a phase shift of $(360 / N)^{\circ}$. Consequently, load current $i_{0}$ is the sum of $N$ pulsating currents. The common load is modeled by a resistance $R$, representing the power in the DC bus. The ripple frequency of the total current is $N$ times the fundamental switching frequency in each single converter. It turns out that the total current ripple is considerably reduced compared to the current ripple in each individual converter, thus reducing the global stress on the FC generator. A typical FC $V-I$ polarization curve is shown in Figure 2. This shows that the FC voltage is a decreasing function of load current density. The wide range voltage variation in $\mathrm{FC}$ generators is due to well-explained chemical causes, e.g., [4, 21].

\subsection{FC-IBC Modeling}

Consider the FC-IBC system of Figure 1 , where $L_{k}(k=1, \ldots$, $N$ ) denotes the inductances in the $N$ cells with equivalent series resistance (ESR) denoted $r_{k}$; the power semiconductors are ideal controlled switches (zero on-state voltages drop, zero offstate current, and instantaneous commutation). The interleaved PWM binary input signal $u_{k}$ of the $k$ th boost converter takes values in the set $\{0,1\}$. By applying Kirchhoff's laws to the circuit of Figure 1 over switching period $T$, one obtains the following instantaneous (switched) model of the $k$ th boost converter:

$$
\begin{aligned}
\frac{d v_{o}}{d t} & =-\frac{1}{R C} v_{o}+\frac{1}{C} \sum_{k=1}^{N}\left(1-u_{k}\right) i_{k}, \\
\frac{d i_{k}}{d t} & =\left(u_{k}-1\right) \frac{v_{o}}{L_{k}}-\frac{r_{k}}{L_{k}} i_{k}+\frac{v_{i n}}{L_{k}} \\
i_{T} & =\sum_{k=1}^{N} i_{k} .
\end{aligned}
$$


The above switched model involves the binary control inputs $u_{k}$, and so it can hardly be based upon in control design. Indeed, most control design approaches apply to systems involving continuously varying control signals [22]. Therefore, the so-called average models are generally resorted to whenever PWM switch converters are involved [23, 24]. When the switching frequency is much greater than the maximum frequency of the circuit, the following average model (Eqs. (2a)-(2c)) is obtained, under slow variation and small ripple, by averaging Eqs. (1a)-(1c) over each cutting period:

$$
\begin{aligned}
\frac{d v_{o}}{d t} & =-\frac{1}{R C} v_{o}+\frac{1}{C} \sum_{k=1}^{N}\left(1-\mu_{k}\right) i_{k}, \\
\frac{d i_{k}}{d t} & =\left(\mu_{k}-1\right) \frac{v_{o}}{L_{k}}-\frac{r_{k}}{L_{k}} i_{k}+\frac{v_{i n}}{L_{k}}, \\
i_{T} & =\sum_{k=1}^{N} i_{k},
\end{aligned}
$$

where $\mu_{k}$ denotes the PWM duty cycle that continuously varies in the real interval $[0,1]$. In Eqs. (2a)-(2c), the voltage and the currents are in fact the average values (over switching periods) of the corresponding instantaneous variables. To avoid multiple notations, the same symbols are used for the instantaneous variables (used in Eqs. (1a) and (1b)) and their average versions (used in Eqs. (2a)-(2c)).

\section{ADAPTIVE OUTPUT FEEDBACK CONTROLLER}

The control objectives will first be formulated in Section 3.1; then, an adaptive output feedback controller will be presented and analyzed in Section 3.2.

\subsection{Control Objectives}

The control objectives are the following:

i. load voltage $v_{o}$ should be tightly regulated to a given reference value $v_{d}$, and

ii. total current $i_{T}$ carried by the IBC must be equally shared between the IBC individual cells.

As pointed out in Section 1, the zero dynamics associated to the load voltage are shown in many places to be instable, making boost power converters non-minimum phase systems [25]. The initial objective can then be reformulated as a current control problem in each individual boost converter. On the other hand, the current-sharing objective means that the same current should be carried by each individual converter. For coherency with this objective, the parallel cells are supposed be identical, which entails the following equalities:

$$
L_{1}=L_{2}=\ldots .=L_{N}=L, r_{1}=r_{2}=\ldots=r_{N}=r .
$$

The common current value, say $i_{d}$, that should circulate in all cells is fixed so that the resulting load voltage equals the desired voltage value $v_{d}$. To this end, the total power balance in the IBC is expressed. Doing so, one gets $v_{i n} i_{T}=\frac{v_{0}^{2}}{R}+$ $r \sum_{k=1}^{N} i_{k}^{2}$, or equivalently,

$$
v_{\text {in }} \sum_{k=1}^{N} i_{k}=\frac{v_{0}^{2}}{R}+r \sum_{k=1}^{N} i_{k}^{2}
$$

Letting $v_{0}=v_{d}$ and $i_{k}=i_{d}(k=1, \ldots, N)$ in Eq. (4), one gets the following second-order equation in $i_{d}$ :

$$
v_{i n} N i_{d}-\frac{v_{d}^{2}}{R}-r N i_{d}^{2}=0 .
$$

It is easily checked that if $v_{d}<\frac{v_{i n}}{2} \sqrt{\frac{N R}{r}}$, then the above equation has two real solutions, i.e., $i_{d}^{1,2}=\frac{v_{i n}}{2 r} \mp \sqrt{\frac{v_{i n}^{2}}{4 r^{2}}-\frac{v_{d}^{2}}{r N R}}$.

Considering that power is continuously varying (i.e., there is no power jump), it follows that only the smaller solution is physical. It turns out that the current reference value is

$$
i_{d}=\frac{v_{i n}}{2 r}-\sqrt{\frac{v_{i n}^{2}}{4 r^{2}}-\frac{v_{d}^{2}}{r N R}} .
$$

The point is that load resistance $R$ cannot be assumed to be known a priori in most practical applications. Therefore, a current reference estimate is considered; i.e.,

$$
\hat{i}_{d}=\frac{v_{i n}}{2 r}-\sqrt{\frac{v_{i n}^{2}}{4 r^{2}}-\frac{v_{d}^{2}}{r N \hat{R}}},
$$

where $\hat{R}$ denotes an online load resistance estimate provided by an adaptive law yet to be determined.

\subsection{Adaptive Output Feedback Controller Design}

Here, one seeks an adaptive controller that regulates well all currents $i_{k}$ to their common reference value $\hat{i}_{d}$ given by Eq. (6) and provides an accurate estimate of $\hat{R}$, specifically one satisfying $\hat{R}(t)-R \underset{t \rightarrow \infty}{\rightarrow} 0$ so that $\hat{i}_{d}-i_{d} \underset{t \rightarrow \infty}{\rightarrow} 0$. The point is that the currents are presently not accessible to measurements. Therefore, the controller design is based on the following current estimator suggested by Eq. (2b):

$$
\frac{d \hat{i}_{k}}{d t}=\left(\mu_{k}-1\right) \frac{v_{o}}{L}-\frac{r}{L} \hat{i}_{k}+\frac{v_{i n}}{L}(k=1 \ldots N) .
$$

Comparing Eqs. (7) and (2b), the current estimation errors

$$
\tilde{i}_{k}=\hat{i}_{k}-i_{k}
$$

are readily checked to undergo the following differential equation:

$$
\tilde{i}_{k}=-\frac{r}{L} \tilde{i}_{k} .
$$


Clearly, this shows that $\tilde{i}_{k}$ is exponentially vanishing. Consequently, the estimators in Eq. (7) can actually be based upon the task of designing current regulators able to drive the tracking errors,

$$
e_{k}=\hat{i}_{k}-\hat{i}_{d}(k=1 \ldots N),
$$

to the origin. First, the trajectory of $e_{k}$ is determined by just differentiating it with respect to time. Doing so, using Eq. (7), one obtains

$$
\dot{e}_{k}=\left(\mu_{k}-1\right) \frac{v_{o}}{L}-\frac{r}{L} \hat{i}_{k}+\frac{v_{i n}}{L}-\dot{\hat{i}}_{d} .
$$

This suggests the following law:

$$
\mu_{k}=1+\frac{1}{v_{o}}\left(r \hat{i}_{k}-v_{i n}+L \dot{\hat{i}}_{d}-k_{1} L e_{k}\right) .
$$

Indeed, combining Eqs. (12) and (11) gives

$$
\dot{e}_{k}=-k_{1} e_{k},
$$

where $k_{1}>0$ is any real constant (a design parameter).

To complete the controller design, one needs an adaptive law providing $\hat{R}$ and $\dot{\hat{R}}$, which are required to get $i_{d}$ and $i_{d}$ using Eq. (6). To this end, notice that the resistance inverse $\theta=1 / R$ enters linearly in the load voltage equation (Eq. (2a)). This, together with the fact that accurate voltage measurements and current estimates are available, suggests the following parameter adaptive law structure:

$$
\begin{aligned}
\frac{d \hat{v}_{o}}{d t} & =-\frac{\hat{\theta}}{C} v_{o}+\frac{1}{C} \sum_{k=1}^{N}\left(1-\mu_{k}\right) \hat{i}_{k}-k_{2} \tilde{v}_{o}, \\
\dot{\hat{\theta}} & =k_{3} \tilde{v}_{o},
\end{aligned}
$$

where $\left(k_{2}, k_{3}\right)$ are adaptation gains to be selected so that the estimation errors

$$
\begin{aligned}
\tilde{v}_{o} & =\hat{v}_{o}-v_{o}, \\
\tilde{\theta} & =\hat{\theta}-\theta
\end{aligned}
$$

are made asymptotically vanishing. To this end, the trajectories of these errors are analyzed. It readily follows, comparing Eqs. (14) and (2a), that the above errors undergo the following differential equations:

$$
\begin{aligned}
\dot{\tilde{v}}_{o} & =-\frac{\tilde{\theta}}{C} v_{o}+\frac{1}{C} \sum_{k=1}^{N}\left(1-\mu_{k}\right) \tilde{i}_{k}-k_{2} \tilde{v}_{o}, \\
\dot{\tilde{\theta}} & =k_{3} \tilde{v}_{o} .
\end{aligned}
$$

The above equations show an interaction with Eqs. (13) and (9), which describe the trajectories of errors $\tilde{i}_{k}$ and $e_{k}$. Therefore, a Lyapunov function involving all errors is considered:

$$
V=\frac{1}{2}\left(\sum_{k=1}^{N} e_{k}^{2}+\sum_{k=1}^{N} \tilde{i}_{k}^{2}+\tilde{v}_{o}^{2}+\tilde{\theta}^{2}\right) .
$$

Clearly, $V$ is a positive definite function of the errors $\left(e_{k}, \tilde{i}_{k}, \tilde{v}_{o}, \tilde{\theta}\right)$. Its derivative along the trajectories of these errors is the following:

$$
\begin{aligned}
\dot{V}= & \sum_{k=1}^{N} e_{k} \dot{e}_{k}+\sum_{k=1}^{N} \tilde{i}_{k} \dot{\tilde{i}}_{k}+\tilde{v}_{o} \dot{\tilde{v}}_{o}+\tilde{\theta} \dot{\tilde{\theta}} \\
= & -k_{1} \sum_{k=1}^{N} e_{k}^{2}-\frac{r}{L} \sum_{k=1}^{N} \tilde{i}_{k}^{2}-k_{2} \tilde{v}_{o}^{2} \\
& +\frac{1}{C} \sum_{k=1}^{N}\left(1-\mu_{k}\right) \tilde{i}_{k} \tilde{v}_{o}+\tilde{\theta}\left(k_{3}-\frac{1}{C} v_{o}\right) \tilde{v}_{o},
\end{aligned}
$$

where Eqs. (19), (18), (13), and (5) have been used to get the last inequality. Furthermore, it is readily checked that $2\left|\tilde{i}_{k} \tilde{v}_{o}\right| \leq \varepsilon \tilde{i}_{k}^{2}+\frac{\tilde{v}_{o}^{2}}{\varepsilon}$, whatever the positive real number $\varepsilon>0$. Then, Eq. (20) gives

$$
\begin{aligned}
\dot{V} & \leq-k_{1} \sum_{k=1}^{N} e_{k}^{2}-\frac{r}{L} \sum_{k=1}^{N} \tilde{i}_{k}^{2}-k_{2} \tilde{v}_{o}^{2}+\frac{1}{C} \sum_{k=1}^{N}\left(\varepsilon \tilde{i}_{k}^{2}+\frac{\tilde{v}_{o}^{2}}{\varepsilon}\right) \\
& +\tilde{\theta}\left(k_{3}-\frac{1}{C} v_{o}\right) \tilde{v}_{o} \\
\leq & -k_{1} \sum_{k=1}^{N} e_{k}^{2}-\left(\frac{r}{L}-\frac{\varepsilon}{C}\right) \sum_{k=1}^{N} \tilde{i}_{k}^{2}-\left(k_{2}-\frac{N}{C \varepsilon}\right) \tilde{v}_{o}^{2} \\
& +\tilde{\theta}\left(k_{3}-\frac{1}{C} v_{o}\right) \tilde{v}_{o}
\end{aligned}
$$

In the light of the above inequality, it is seen that the design parameters must be chosen as follows:

$$
k_{1}>0, \quad k_{3}=v_{o} / C,
$$

and $k_{2}>N /(2 C \varepsilon)$, where $\varepsilon>0$ is any real number such that $(r / L)>(\varepsilon / 2 C)$. This suggests letting $\varepsilon /(2 C)=\left(1-\lambda_{1}\right) r / L$ and

$$
k_{2}=\frac{N L}{C^{2} r\left(1-\lambda_{1}\right)}+\lambda_{2}
$$

for some $0<\lambda_{1}<1$ and $\lambda_{2}>0$. Using Eqs. (22)-(24), the inequality of Eq. (22) implies

$$
\dot{V} \leq-k_{1} \sum_{k=1}^{N} e_{k}^{2}-\lambda_{1} \frac{r}{L} \sum_{k=1}^{N} \tilde{i}_{k}^{2}-\lambda_{2} \tilde{v}_{o}^{2},
$$

which shows that $\dot{V}$ is a negative semi-definite of $\left(e_{k}, \tilde{i}_{k}, \tilde{v}_{o}\right)$. This completes the control design task. For convenience, the adaptive controller thus developed is summarized in Table 1.

The adaptive controller of Table 1 is further illustrated by Figure 3. This shows that the main component of the controller is the control law described by Eq. (30), which generates the control signals $\left(\mu_{1}, \ldots, \mu_{N}\right)$ that are applied to the physical power converter (represented by the model in Eqs. (1a)-(1c)) 


$$
\begin{aligned}
& \frac{d \hat{i}_{k}}{d t}=\left(\mu_{k}-1\right) \frac{v_{o}}{L}-\frac{r}{L} \hat{i}_{k}+\frac{v_{i n}}{L}(k=1 \ldots N), \\
& \frac{d \hat{v}_{o}}{d t}=-\frac{\hat{\theta}}{C} v_{o}+\frac{1}{C} \sum_{k=1}^{N}\left(1-\mu_{k}\right) \hat{i}_{k}-k_{2} \tilde{v}_{o}, \\
& \dot{\hat{\theta}}=k_{3} \tilde{v}_{o}, \\
& \hat{i}_{d}=\frac{v_{i n}}{2 r}-\sqrt{\frac{v_{i n}^{2}}{4 r^{2}}-\frac{v_{d}^{2}}{r N \hat{R}}}, \\
& \mu_{k}=1+\frac{1}{v_{o}}\left(r \hat{i}_{k}-v_{i n}+L \dot{\hat{i}}_{d}-k_{1} L e_{k}\right),
\end{aligned}
$$

where $k_{1}>0,0<\lambda_{1}<1$, and $\lambda_{2}>0$ are freely chosen design parameters; $k_{2}=\frac{N L}{4 C^{2} r\left(1-\lambda_{1}\right)}+\lambda_{2}$; and $k_{3}=\frac{1}{C} v_{o}$.

TABLE 1. Adaptive output feedback controller operation

through the PWM module. Normally, the implementation of this control necessitates the currents $\left(i_{1}, \ldots, i_{N}\right)$ and the value of load $R$. Since $\left(i_{1}, \ldots, i_{N}\right)$ are not accessible to measurements and $R$ is not known, the controller is augmented with estimators, namely Eqs. (27) and (28), providing the control law with online estimates of the unavailable variables and parameters. In the control literature (e.g., [22]), a controller that involves online estimation of the system states is commonly referred to as output feedback, and when it involves online estimation of some parameters, it is called adaptive. In this respect, the proposed controller is adaptive and output feedback.

\subsection{Theoretical Controller Performance Analysis}

The closed-loop control performances are described in the next theorem, which constitutes the main result.

Theorem 1. Consider the FC-IBC system, represented by the model in Eqs. (2a)-(2c), in closed loop with the adaptive output feedback controller of Table 1. Then, the error vector $\left(e_{k}, \tilde{i}_{k}, \tilde{v}_{o}, \tilde{\theta}\right)$ is globally asymptotically vanishing.

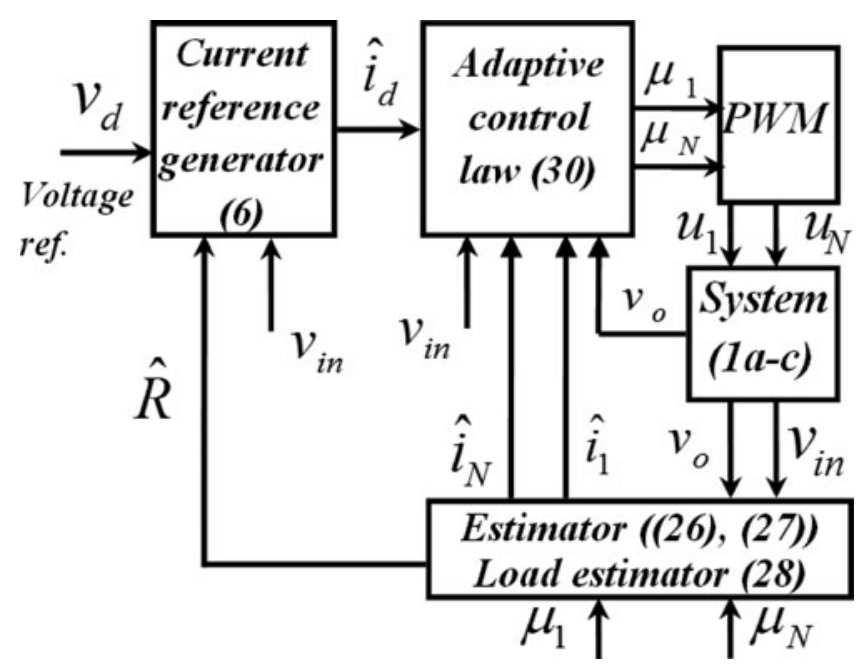

FIGURE 3. Adaptive and output feedback diagram of the FC-IBC system.
Proof. First, the equations that describe the trajectories of the errors $\left(e_{k}, \tilde{i}_{k}, \tilde{v}_{o}, \tilde{\theta}\right)$ are recapitulated. It readily follows from Eqs. (13), (9), (18), and (19) that

$$
\begin{aligned}
\dot{e}_{k} & =-k_{1} e_{k}, \\
\dot{\tilde{i}}_{k} & =-\frac{r}{L} \tilde{i}_{k}, \\
\dot{\tilde{v}}_{o} & =-\frac{\tilde{\theta}}{C} v_{o}+\frac{1}{C} \sum_{k=1}^{N}\left(1-\mu_{k}\right) \tilde{i}_{k}-k_{2} \tilde{v}_{o}, \\
\dot{\tilde{\theta}} & =k_{3} \tilde{v}_{o} .
\end{aligned}
$$

It is easily checked from Eqs. (20) that $V$ is a Lyapunov function of the system in Eqs. (31)-(34), as it is a positive definite function of $\left(e_{k}, \tilde{i}_{k}, \tilde{v}_{o}, \tilde{\theta}\right)$ and $V \rightarrow \infty$ as $\left\|\left[e_{k}, \tilde{i}_{k}, \tilde{v}_{o}, \tilde{\theta}\right]\right\| \rightarrow \infty$. Furthermore, it is readily seen from Eq. (25) that the derivative of $V$, along the trajectory of Eqs. (31)-(34), is semi-negative definite. Then it follows that by applying standard Lyapunov stability theorems the origin $(0,0,0,0)$ is stable. Furthermore, if follows from Lasalle's invariance principle (see, e.g., [22]) that the error vector $\left(e_{k}, \tilde{i}_{k}, \tilde{v}_{o}, \tilde{\theta}\right)$ converges to the largest invariant set $M$ contained in the subset $Z=\left\{[0,0,0, x]^{T}, x \in \mathbf{R}\right\}$. Now, it is shown that $M$ is reduced to the origin. To this end, consider any vector $[0,0,0, x]^{T} \in M$ for some real $x$, and suppose that $\left[e_{k}(0), \tilde{i}_{k}(0), \tilde{v}_{o}(0), \tilde{\theta}(0)\right]=[0,0,0, x]$. Since $M$ is invariant, it follows that $\left[e_{k}(t), \tilde{i}_{k}(t), \tilde{v}_{o}(t), \tilde{\theta}(t)\right] \in M$ for all $t>0$. Since $M \subset Z$, it follows that

$$
e_{k}(t)=\tilde{i}_{k}(t)=\tilde{v}_{o}(t)=0, \text { for all } t>0 .
$$

Using Eq. (35), one gets from Eq. (34) that $\dot{\tilde{\theta}}=0$, which implies in turn that $\tilde{\theta}(t)=x$ for all $t>0$. Then, one gets from Eqs. (33) and (35) that $0=\dot{\tilde{v}}_{o}(t)=-\left(x v_{o}(t)\right) / C$. This implies that $x=0$, except for the pathological case where output voltage $v_{o}(t)$ is identically null. This case is simply ruled out by letting the capacitor be initially charged, which is always possible. Hence, the invariant set $M$ is reduced to the origin, which implies that all errors, including $\tilde{\theta}$, are asymptotically vanishing. This completes the proof of Theorem 1.

Remark 1. Theorem 1 shows that the adaptive controller of Table 1 performs well. In particular, it is guaranteed that the tracking errors of interest, i.e., $i_{k}-i_{d}(k=1 \ldots N)$, are all asymptotically vanishing. Indeed, one has from Eqs. (8) and (10) that $i_{k}-i_{d}=i_{k}-\hat{i}_{k}+\hat{i}_{k}-\hat{i}_{d}=-\tilde{i}_{k}+e_{k}$. This clearly implies that $i_{k}(t)-i_{d}(t) \underset{t \rightarrow \infty}{\rightarrow} 0$ by Theorem 1 .

\section{SIMULATION RESULTS}

In this section, the performances of the adaptive output feedback controller of Table 1 are illustrated by simulation. The controlled FC-IBC includes an FC generator with the 
characteristic of Figure 2, while the IBC circuit involves three parallel boost converters with the characteristics of Table 2. The unknown load is subject to a series of step changes. Owing to the controller, it has already been noticed that the control action $\mu_{k}$ represents the PWM duty cycle, and so it is physically limited to the interval $0 \leq \mu_{k} \leq 1$. The point is that the control law in Eq. (27) may, in transient periods, yield values outside that interval. This issue is practically coped with by implementing the saturated version of Eq. (27), i.e.,

$$
\begin{aligned}
\mu_{k} & =\operatorname{sat}\left(\partial_{k}\right), \\
\partial_{k} & =1+\frac{1}{v_{o}}\left(r \hat{i}_{k}-v_{i n}+L \dot{\hat{i}}_{d}-k_{1} L e_{k}\right),
\end{aligned}
$$

where $\operatorname{sat}($.) denotes the saturation function defined as follows:

$$
\operatorname{sat}(x)=\left\{\begin{array}{ll}
x & \text { if } 0 \leq x \leq 1 \\
1 & \text { if } x>1 \\
0 & \text { if } x<0
\end{array} .\right.
$$

In summary, the implemented controller remains that of Table 1, except that Eqs. (36) and (37) are substituted to Eq. (27). The involved parameters are given the following values, which proved to be convenient: $k_{1}=500$ and $k_{2}=6.25 \times 10^{6}$. The above values have been selected using the trial-and-error rule, bearing in mind the considerations described by Eqs. (30) and (31). The numerical simulation is performed using MATLAB ${ }^{\circledR} /$ Simulink software (The MathWorks, Natick, Massachusetts, USA) according to the diagram of Figure 3. To illustrate the proposed adaptive controller performances, several simulated scenarios are considered, including output voltage tracking of varying reference signals, output voltage regulation in the presence of varying load, controller robustness to inductance changes, and controller behavior in the presence of discontinuous conduction mode (DCM).

\subsection{Controller Tracking Performances}

The capability of the proposed adaptive controller to ensure a perfect output voltage tracking is presently illustrated considering a square reference signal switching between 60 and $90 \mathrm{~V}$. Meanwhile, the unknown load is kept constant, equal

\begin{tabular}{l|cc} 
Parameter & Symbol & Value \\
\hline Number of phases & $N$ & 3 \\
Inductance & $L$ & $50 \mathrm{mH}$ \\
Inductance ESR & $r$ & $1.2 \Omega$ \\
Output capacitor & $C$ & $1000 \mu \mathrm{F}$ \\
Switching frequency & $f_{s}$ & $10 \mathrm{kHz}$
\end{tabular}

TABLE 2. FC-IBC characteristics

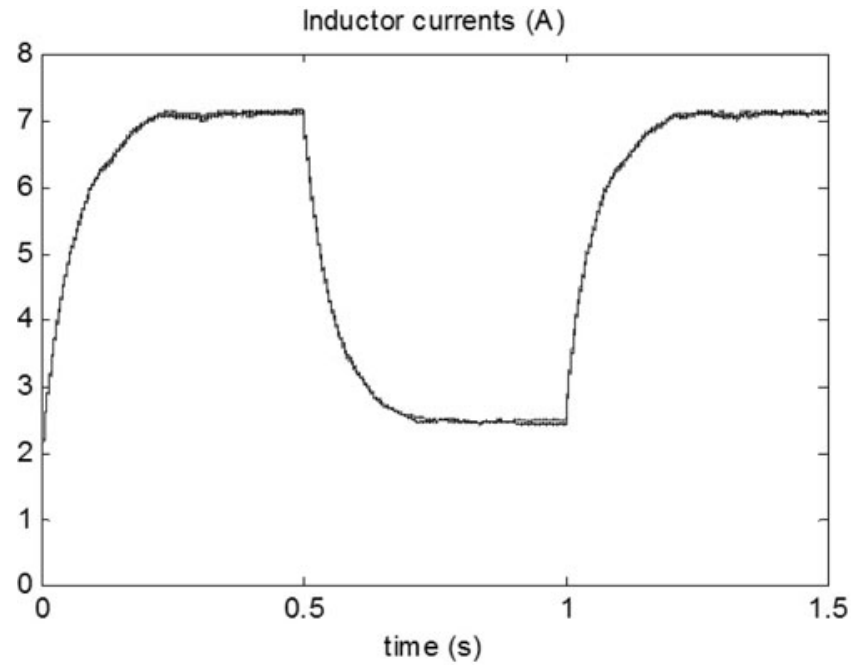

FIGURE 4. Measured currents $i_{1}, i_{2}$, and $i_{3}$ in the presence of constant load and output voltage reference step changes (the three curves are indistinguishable).

to $10 \Omega$. The obtained controller performances are shown in Figures 4 to 7 . Figure 4 shows the equal current sharing between the three cells. Then the three duty cycle signals turn out to be identical to Figure 5. Figure 6 illustrates the good tracking quality of the control as the output voltage tracks well its reference. Finally, Figure 7 shows the FC voltage.

\subsection{Output Voltage Regulation in Presence of Varying Load}

Here, the voltage reference is maintained constant, $v_{d}=60 \mathrm{~V}$, whereas the unknown load is made time varying. Specifically,

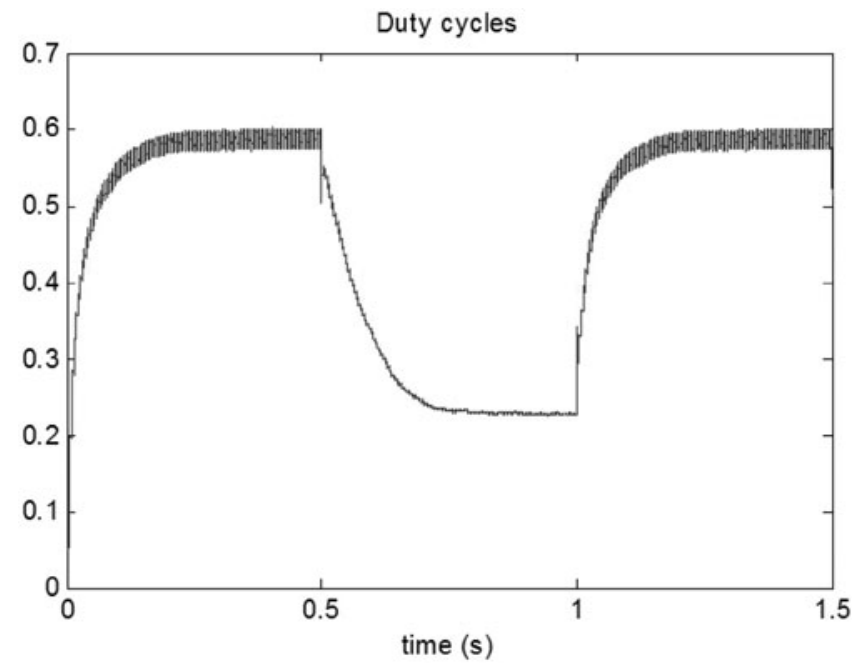

FIGURE 5. Duty-cycle inputs $\mu_{1}, \mu_{2}$, and $\mu_{3}$ in the presence of constant load (the three curves are indistinguishable). 


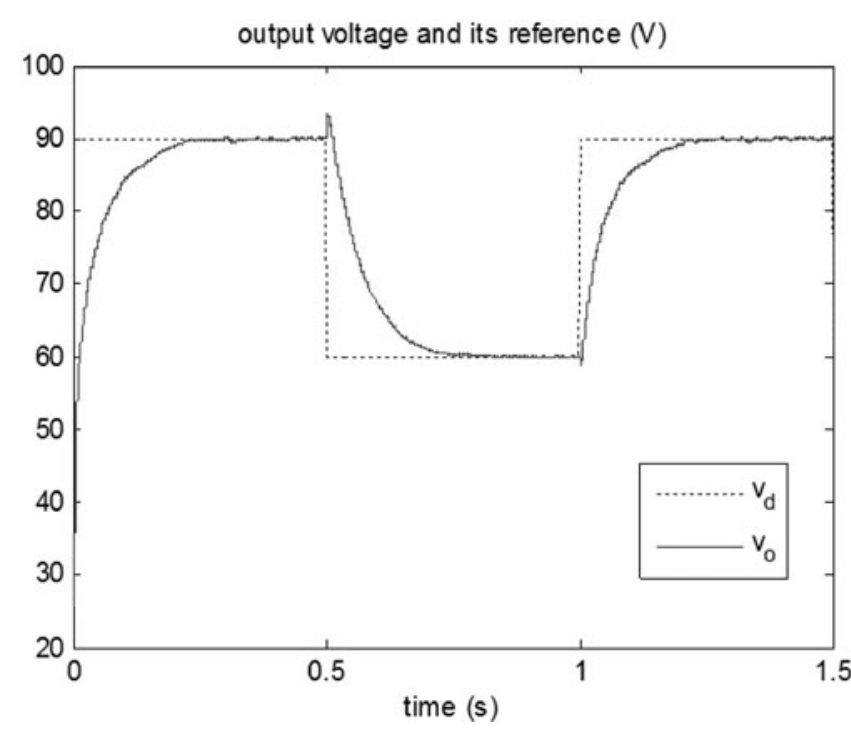

FIGURE 6. Output voltage $v_{o}$ (solid) and voltage reference $v_{d}$ (dashed) in the presence of constant load and output reference step changes.

the load resistance value is switching between 10 and $20 \Omega$ (the step changes are produced at times 0.5 and $1 \mathrm{sec}$, respectively). Figure 8 illustrates the good tracking quality of the controller, and Figure 9 shows the equal current sharing between the three cells.

\subsection{Controller Robustness to Inductance Changes}

Power converter components may vary even during normal operation conditions, e.g., due to changes in operation conditions.

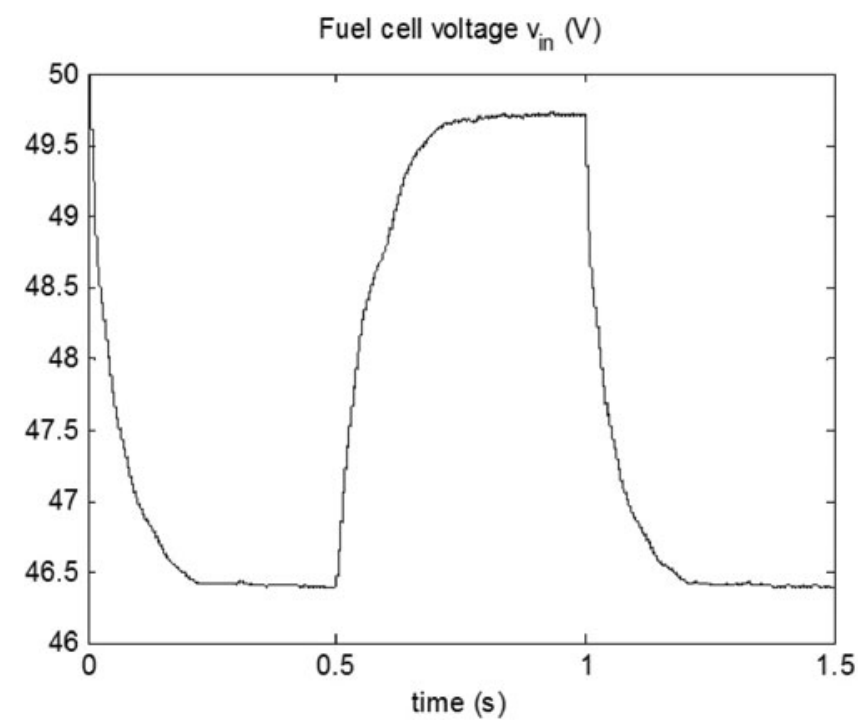

FIGURE 7. FC voltage $v_{i n}$ in the presence of constant load and output reference step changes.

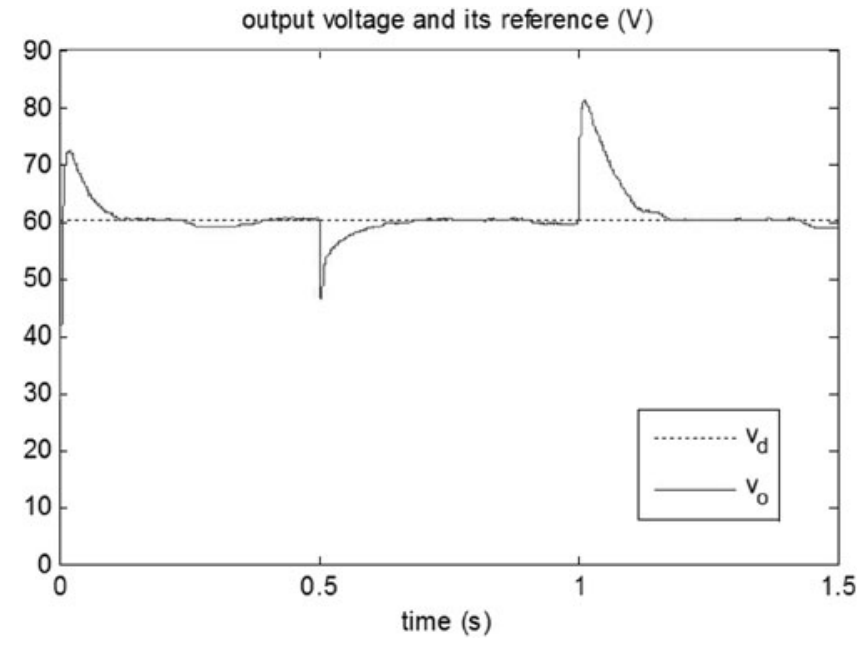

FIGURE 8. Output voltage $v_{o}$ (solid) and constant voltage reference $v_{d}$ (dashed) in the presence of load step changes.

Presently, this mainly concerns the inductances that may see their values vary because of the magnetic core saturation. Therefore, it is of interest to evaluate the performances of the proposed controller in the presence of inductance uncertainty. Figure 10 illustrates the regulation quality in the presence of the variations of $L_{k}$. Specifically, the inductances $\left(L_{1}, L_{2}, L_{3}\right)$, respectively, undergo a deviation of 10,15 , and $20 \%$ from their common nominal value. Meanwhile, one continues to use the nominal value in the controller. The change in $L_{k}$ is successively produced at times $0.5,0.8$, and $1.1 \mathrm{sec}$. Figure 10 shows that the quality of output voltage regulation is still quite satisfactory, despite inductance uncertainty. Figure 11 shows that the current sharing requirement is still satisfactorily met.

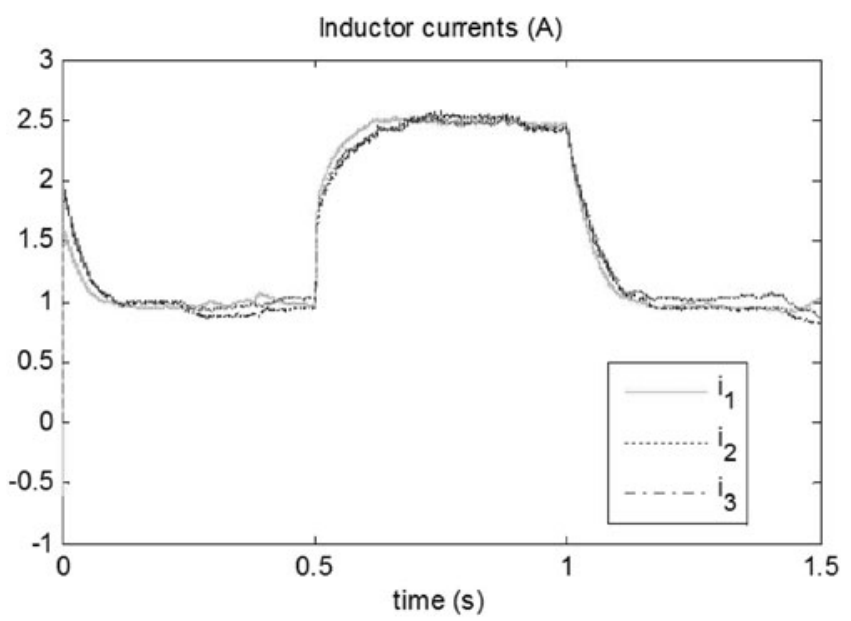

FIGURE 9. Measured currents $i_{1}, i_{2}$, and $i_{3}$ in the presence of load step changes and constant output voltage reference. The three curves are too close to be indistinguishable. 


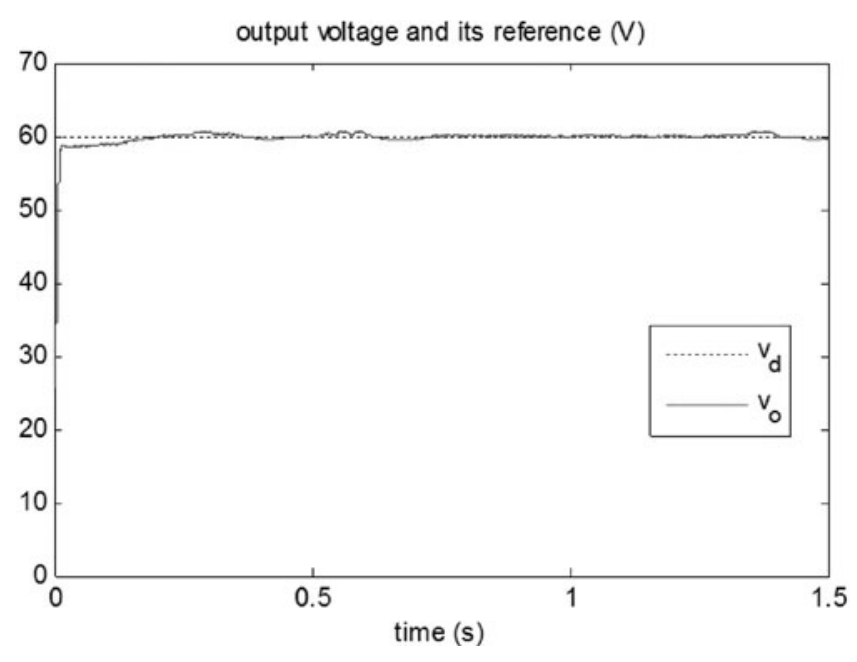

FIGURE 10. Output voltage $v_{o}$ (solid) and constant voltage reference $v_{d}$ (dashed) in the presence of inductances uncertainties. The tracking quality is so good that the curves are hardly distinguishable.

\subsection{Controller Behavior in Presence of DCM}

In practice, DC-DC converters may enter into a DCM operation. This means that in each switching period, the current may vanish during a time interval. The point is that such the phenomenon is not accounted for in the control model (Eqs. (2a)-(2c)), which is based on control design. Therefore, it is of interest to check whether the proposed adaptive controller preserves its performances when it faces such converter behavior. To push the converter into discontinuous mode operation, a sudden and drastic change of the load is produced at time instant $0.5 \mathrm{sec}$ (Figure 12). Then, a drastic decrease of inductor currents is produced that makes the converter operate in

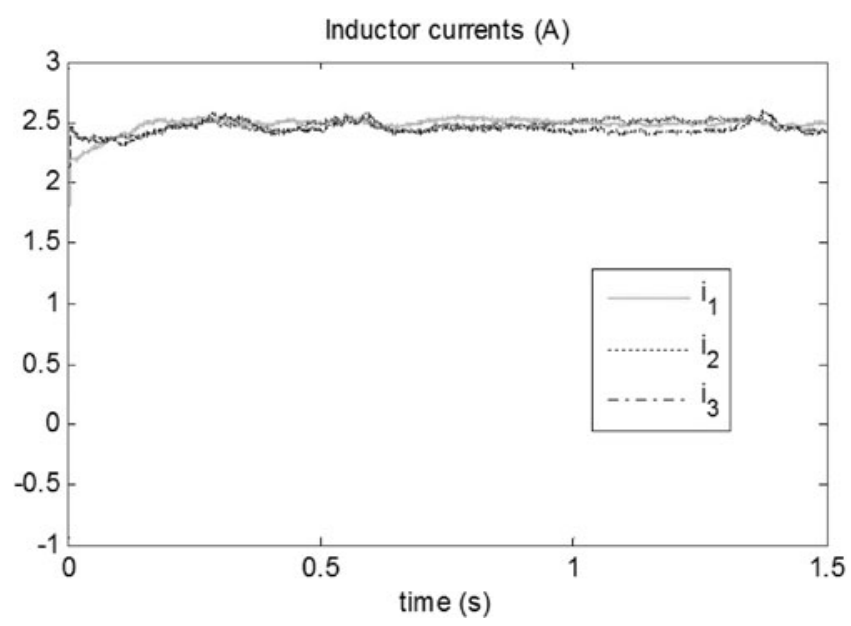

FIGURE 11. Measured currents $i_{1}, i_{2}$, and $i_{3}$ in the presence of inductances uncertainties. Current sharing quality is so good that the three currents are hardly distinguishable. (a)

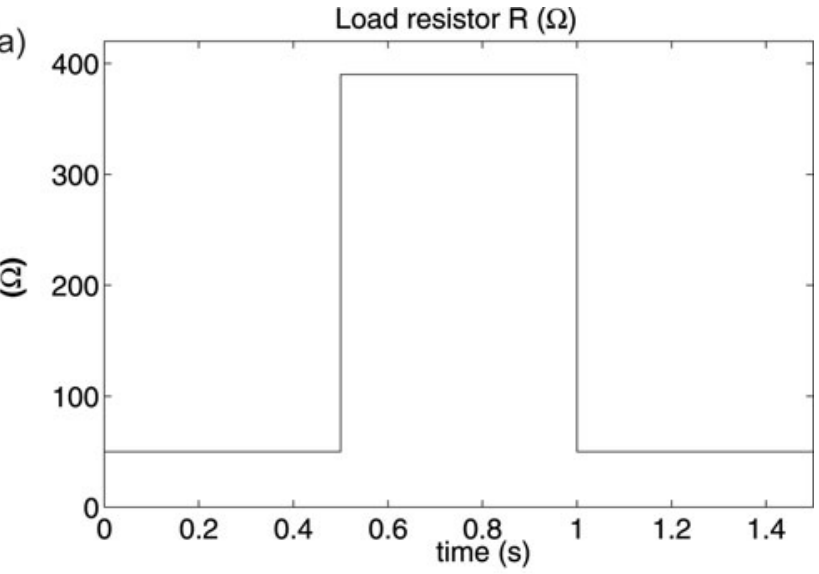

(b)

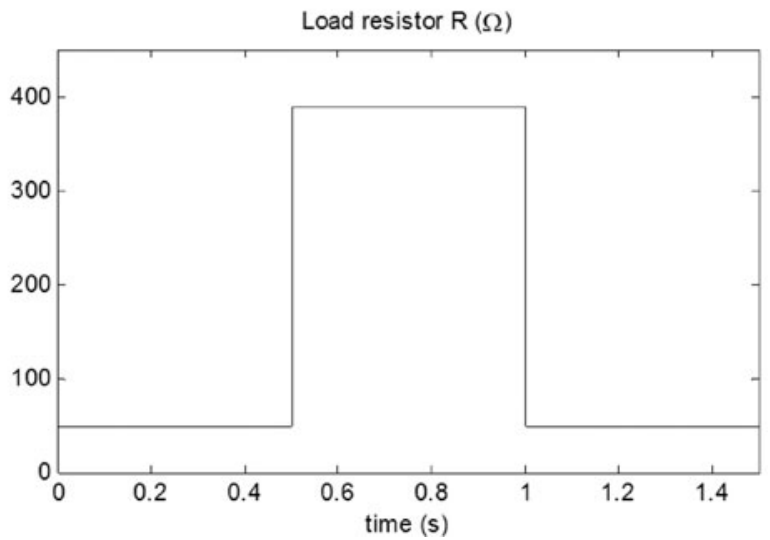

FIGURE 12. Load resistor changes.

discontinuous mode during an interval following the sudden load change. This is illustrated making a zoom on inductor current $i_{1}$ (Figure 13). Figure 14 shows that the proposed controller is able to face discontinuous mode keeping a tight output

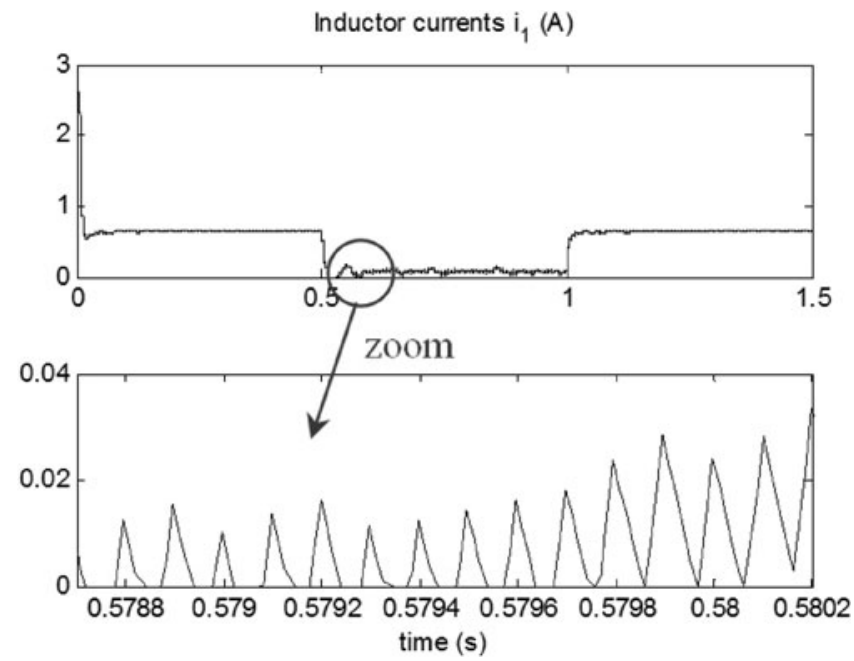

FIGURE 13. Measured currents $i_{1}$ in discontinuous operation mode produced by sudden load change. 

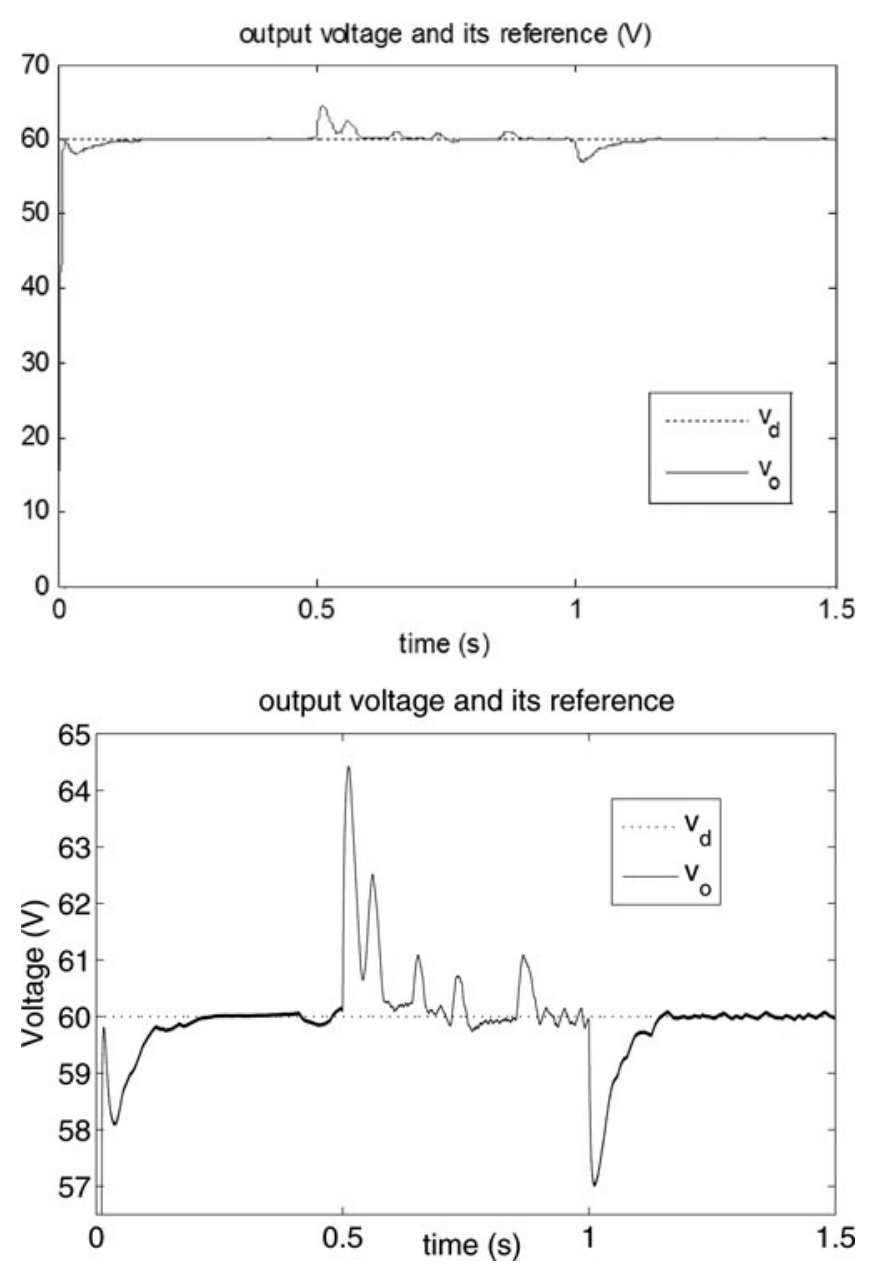

FIGURE 14. Output voltage $v_{o}$ (solid) and constant voltage reference $v_{d}$ (dashed) in discontinuous operation mode produced by sudden load change. The tracking quality is so good that it makes the two curves indistinguishable.

voltage regulation (the output voltage is regulated to its desired value of $60 \mathrm{~V}$ ). Furthermore, Figure 15 shows that the currentsharing requirement in the presence of load changes is also preserved despite the DCM.

\subsection{Linear Control Limits}

To illustrate the supremacy of the proposed output feedback non-linear adaptive controller over traditional linear control methods, linear PI regulators are presently considered within the simulated experimental setup of Figure 16. There PI-1 and PI-2 are PI regulators designed on the basis of the small-signal model of the single boost converter and tuned using Sisotool ${ }^{\circledR}$ (a part of the Control Toolbox Matlab, Mathworks Inc.) software integrated in MATLAB. Accordingly, the regulators are optimized to satisfy some design requirements, such as phase margin (PM), gain margin (GM), and settling time. Doing so,

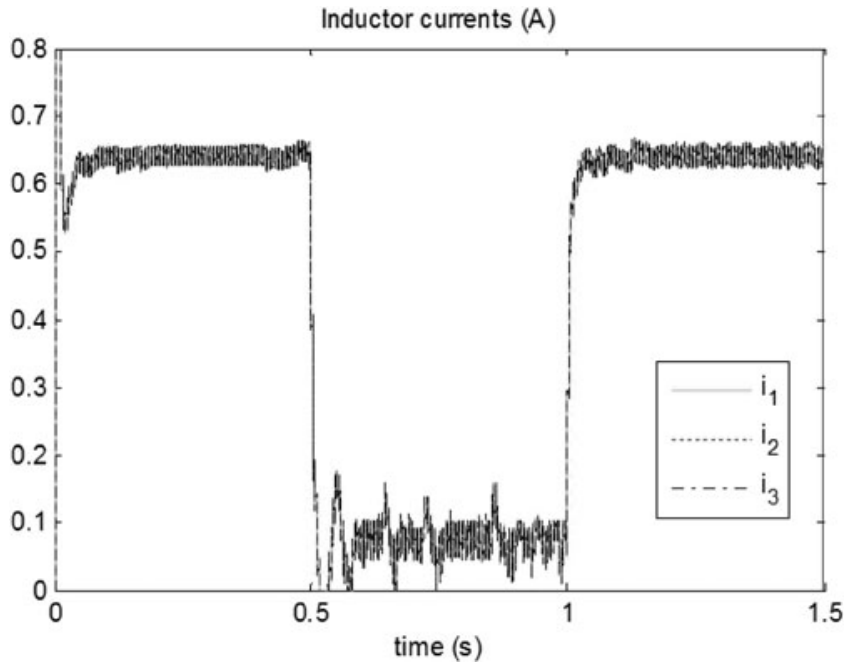

FIGURE 15. Measured currents $i_{1}, i_{2}$, and $i_{3}$ in discontinuous operation mode. Current sharing quality is so accurately realized that the three currents are indistinguishable.

the following transfer functions of regulators PI-1 and PI-2 are, respectively, retained:

$$
C_{1}(s)=4 \frac{1+0.01 s}{s}, \quad C_{2}(s)=200 \frac{1+0.005 s}{s},
$$

as they lead to the satisfactory performances, specifically PM $=45^{\circ}$ and $\mathrm{GM}=10 \mathrm{~dB}$. The resulting control performances are illustrated by Figures 17 and 18 .

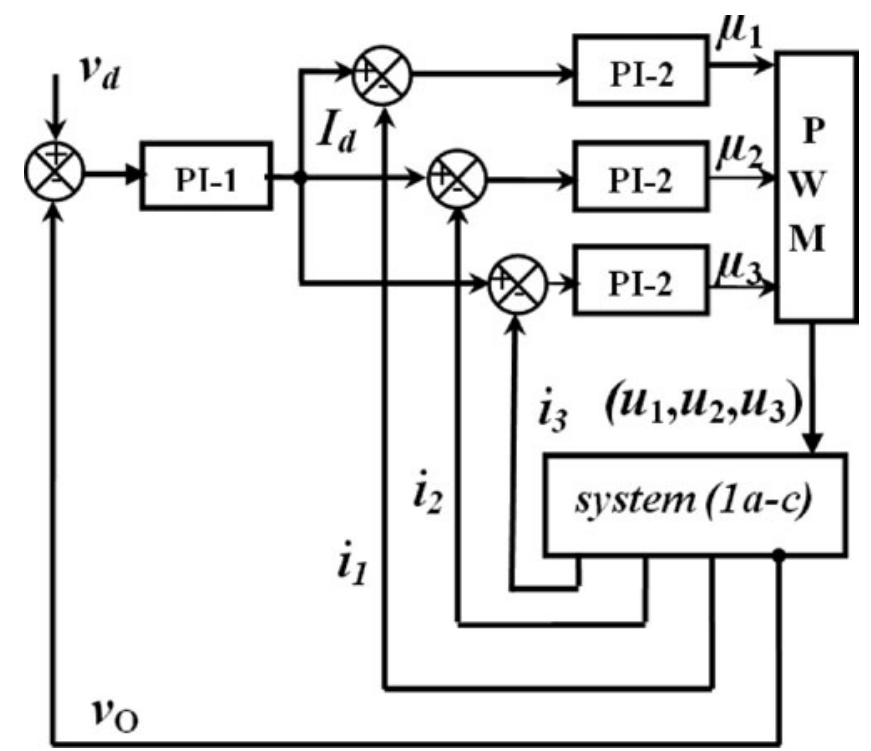

FIGURE 16. Experimental bench for FC-IBC linear control strategy. 

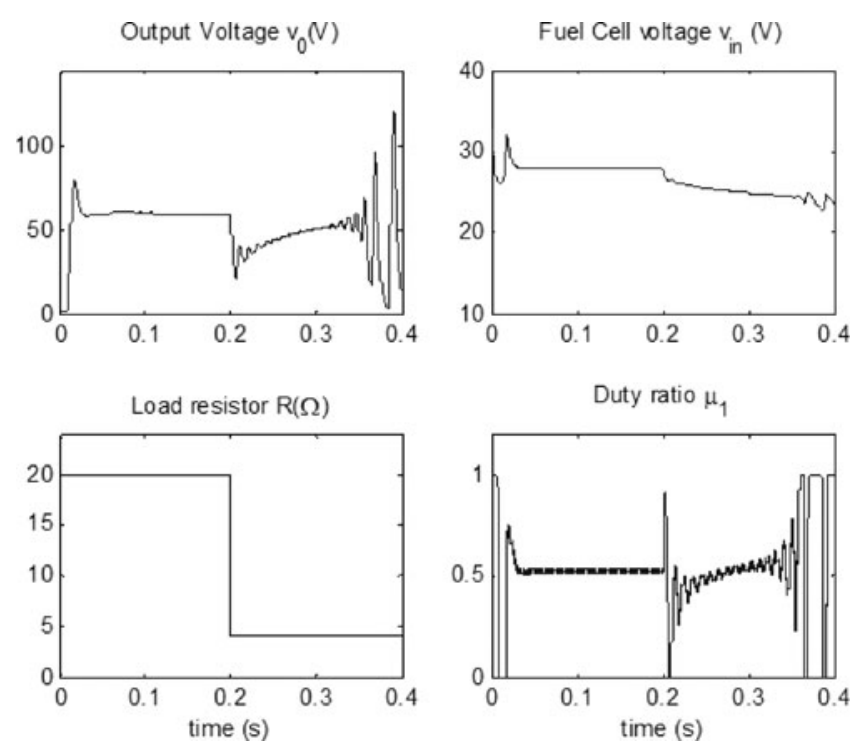

FIGURE 17. Closed-loop performances of linear controller in presence of load step changes.

\subsubsection{Linear Control Performances in the Presence of a Varying Load.}

The simulations show clearly that the linear PI-based control strategy performs well as long as the system operates around its nominal operation point, unlike the non-linear strategy that maintain a high level of performances in all operation conditions, thanks to its adaptation capability. The deterioration of the linear control strategy performances (when the system deviates from its nominal operation point) is presently worsened
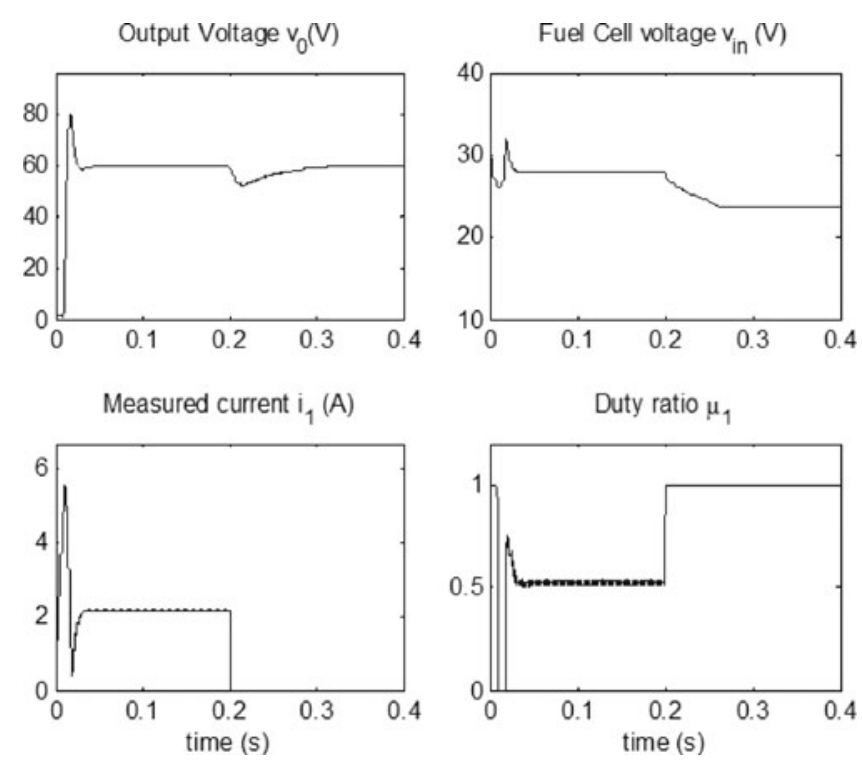

FIGURE 19. Closed-loop performances of linear controller in the presence of sensor fault.

by the presence of the control input limitation. The presence of both input limitation and an integrator in the controller make the closed-loop system suffer from what is commonly called the "windup effect." This means that the system signals are likely to diverge if a disturbance affects the system. Presently, the disturbance is produced by the modeling error resulting from the load resistance uncertainty.
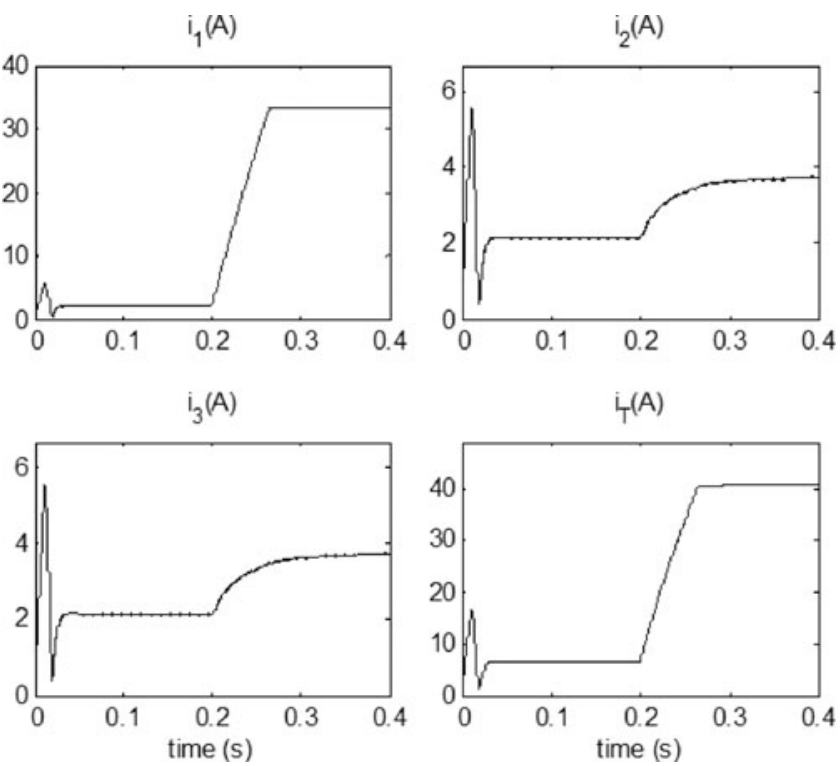

FIGURE 20. Inductors currents with linear controller in the presence of sensor fault.

presence of load step changes. 

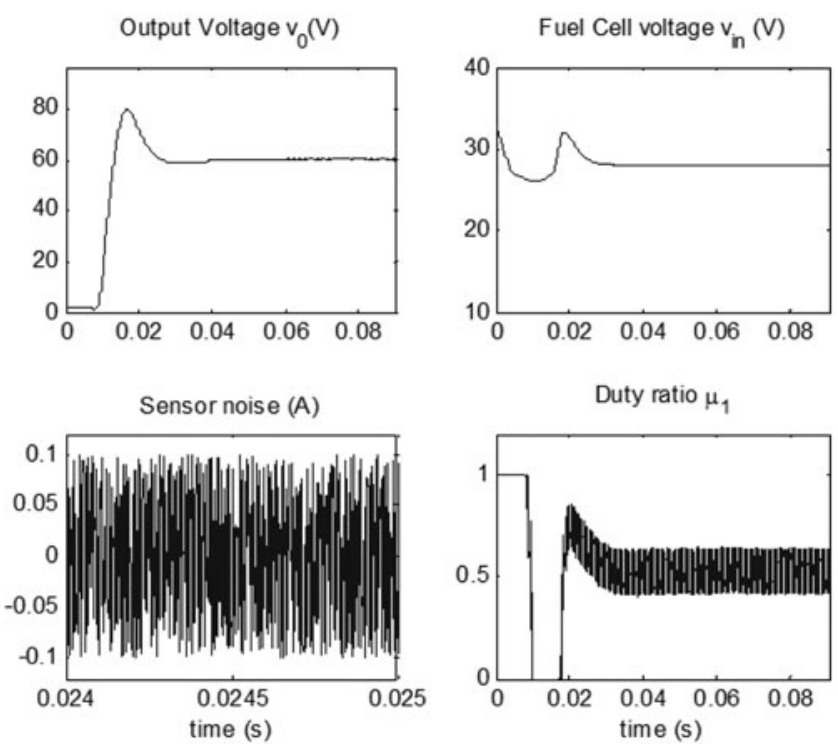

FIGURE 21. Closed-loop performances of linear controller in the presence of sensor noise.

\subsubsection{Linear Control Performances in the Presence of a Sensor Fault}

One major feature of the adaptive non-linear controller developed is this article is its capability of achieving its control objective (including the equal current sharing in the IBC parallel branches) without requiring current sensors in the IBC branches. This sensorless feature provides the proposed nonlinear control strategy with a higher reliability compared to standard control solutions involving current sensors. This re-
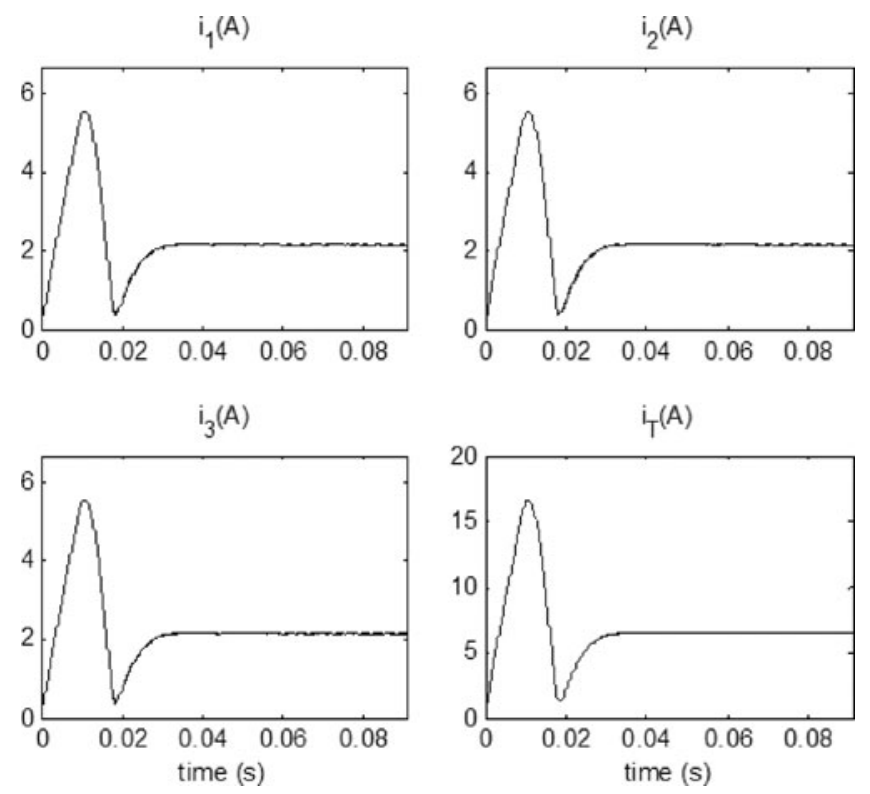

FIGURE 22. Inductors currents with linear controller in the presence of sensor noise.

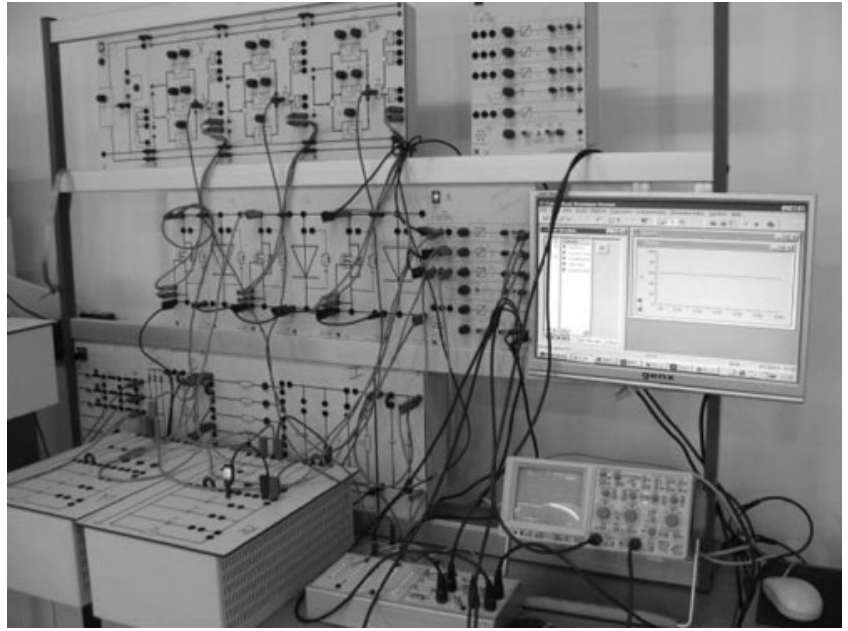

FIGURE 23. Photograph of the experimental setup.

liability issue in standard control solutions is presently illustrated considering again the linear control strategy, involving the PI regulators of Section 4.5.1. The simulated operation protocol is such that the current sensor providing the measurements of current $i_{1}$ breaks down at $0.2 \mathrm{sec}$ (see Figure 19). Specifically, it is considered that starting from that time, the measure of $i_{1}$ provided by the corresponding sensor is null, whereas the true current value is not (Figure 20). It is seen from Figure 19 that the current sharing requirement is perfectly satisfied before the sensor time failure (i.e., $0.2 \mathrm{sec}$ ) and is lost after that time.

\begin{tabular}{|c|c|c|}
\hline Components & Value or reference & Type \\
\hline Dspace & ds 1102 & \\
\hline Diode & BY 329 & $\begin{array}{l}\text { Glass-passivated } \\
\text { double-diffused rectifier } \\
\text { diode }\end{array}$ \\
\hline Transistor & IRF 3808 & MOSFET transistor \\
\hline $\begin{array}{l}\text { Tunable inductances } \\
\mathrm{L}_{\mathrm{i}}(\mathrm{i}=1,2,3)\end{array}$ & $\mathrm{L}_{\mathrm{i}}=100 \mathrm{mH}$ & $E S R r_{i}=2 \Omega$, ferrite cored \\
\hline Capcitor $\mathrm{C}$ & $\mathrm{C}=1200 \mu \mathrm{F}$ & $\begin{array}{l}\text { Aluminum electrolytic type } \\
\text { and maximal voltage } \\
400 \mathrm{~V}\end{array}$ \\
\hline $\begin{array}{l}\text { Variable load } \\
\text { resistance } \mathrm{R}\end{array}$ & $220 \Omega$ & \\
\hline$V_{\text {in }}(\mathrm{DC}$ source $)$ & $40 \mathrm{~V}$ & \\
\hline Series resistance & $2 \Omega$ & \\
\hline Switching frequency & $10 \mathrm{kHz}$ & \\
\hline
\end{tabular}




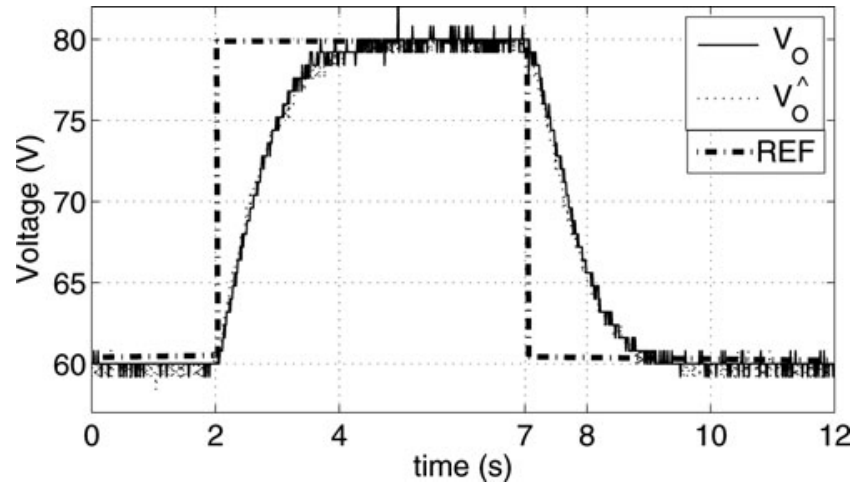

FIGURE 24. Output voltage $v_{o}$ (dashed), its estimate (dotted), and its voltage reference (solid). Constant load and output reference step changes. The output voltage and its estimate are so close that the corresponding curves are hardly distinguishable.

\subsubsection{Linear Control Performances in the Presence of Sensor Noise.}

In addition to a higher reliability, the adaptive non-linear controller developed in this article enjoys its insensitivity to current measurement noise, unlike standard control solutions involving current sensors. The measurement noise effect is presently illustrated considering the PI-based controller of Section 4.5.1. To this end, a noise with amplitude randomly distributed in the interval $[-0.1,0.1]$ is added to the three currents $\left(i_{1}, i_{2}, i_{3}\right)$, and the noisy currents are used in the PIbased controller. The resulting signals are displayed by Figures 21 and 22. The latter shows that the noise amplitude is less than $5 \%$ of the current final value, and consequently, the objectives of output voltage regulation and current sharing are still satisfactorily realized. However, the price paid is a higher control activity, as illustrated by the curve representing $\mu_{1}$ (Figure 21).

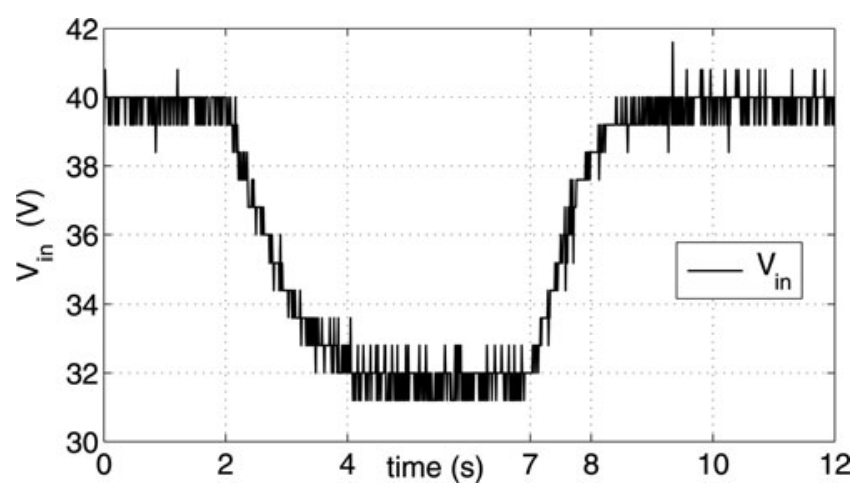

FIGURE 25. Input voltage $v_{i n}$ in the presence of constant load and output voltage reference steps.

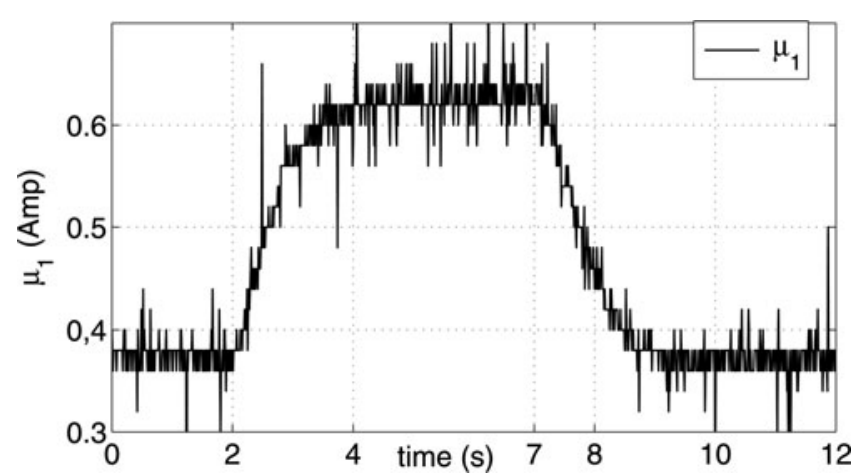

FIGURE 26. Duty-cycle input signal $\mu_{1}$ in the presence of constant load and output voltage reference steps.

\section{EXPERIMENTAL RESULTS}

The proposed controller is now experimentally evaluated considering the laboratory experimental setup depicted in Figure 23. A DC voltage source with a series resistance is used to emulate the FC generator. Indeed, this configuration corresponds to the linear part of the FC generator characteristic (see Figure 1), which is the commonly used part. The DC voltage source delivers $40 \mathrm{~V}$ and a maximal current of $10 \mathrm{~A}$. The IBC is composed of three parallel boost converters. As shown by Figure 1, the converters are identically constituted of:

- tunable decoupled high-frequency input inductances $L_{i}$ $=100 \mathrm{mH}(i=1,2,3)$ with ESR $r_{i}=2 \Omega$;

- main power switches (power MOSFET transistors) of type IRF 3808: $75 \mathrm{~V}$ and $140 \mathrm{~A}$;

- rectifier diodes of type BY 329: $1200 \mathrm{~V}$ and 8 A;

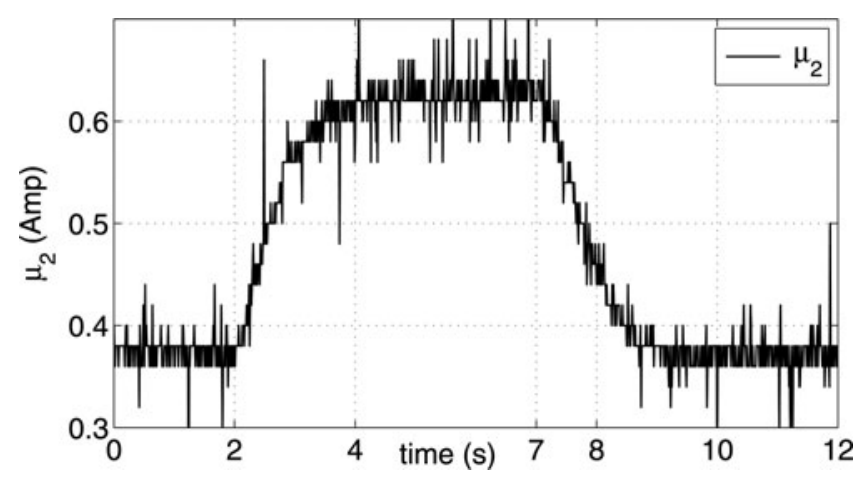

FIGURE 27. Duty-cycle input signal $\mu_{2}$ in the presence of constant load and output reference step. 


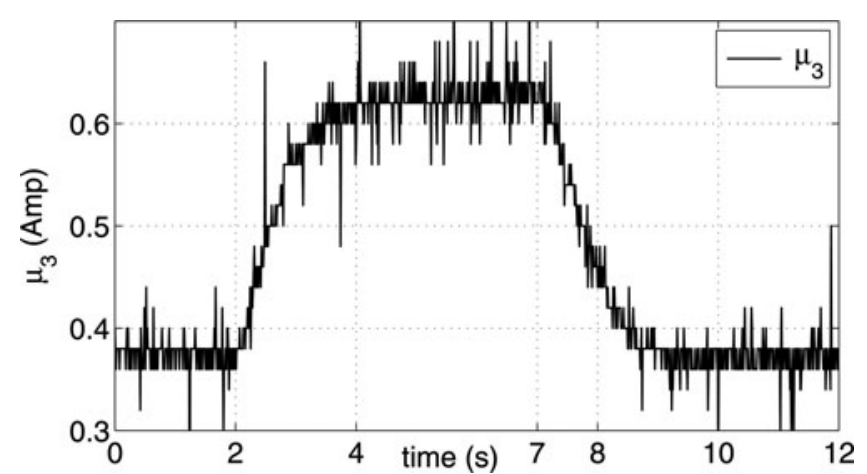

FIGURE 28. Duty-cycle input signal $\mu_{3}$ in the presence of constant load and output voltage reference steps.

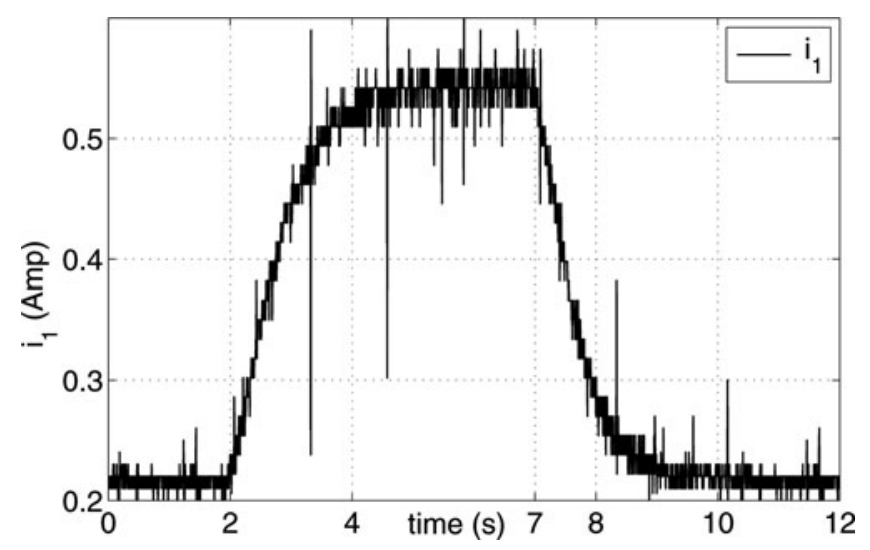

FIGURE 29. Current $i_{1}$ in the presence of constant load and output voltage step changes.

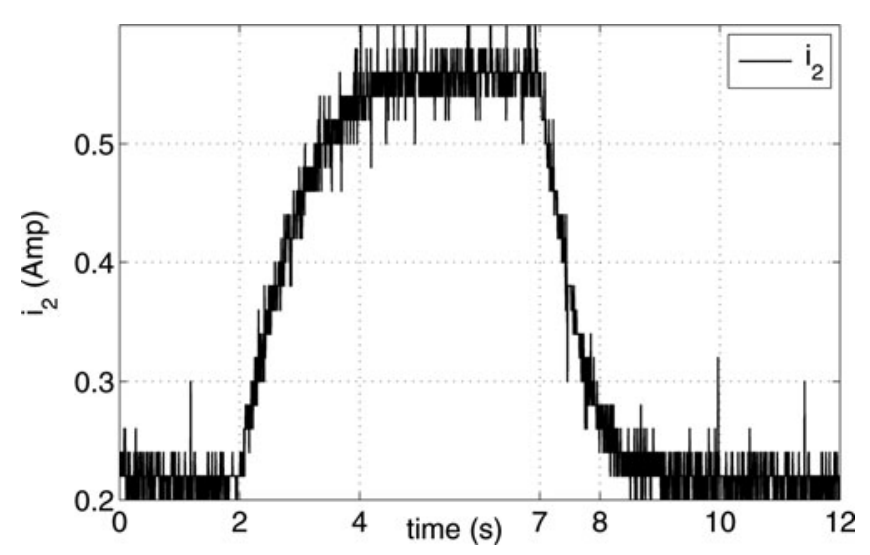

FIGURE 30. Current $i_{2}$ in the presence of constant load and output voltage reference steps.

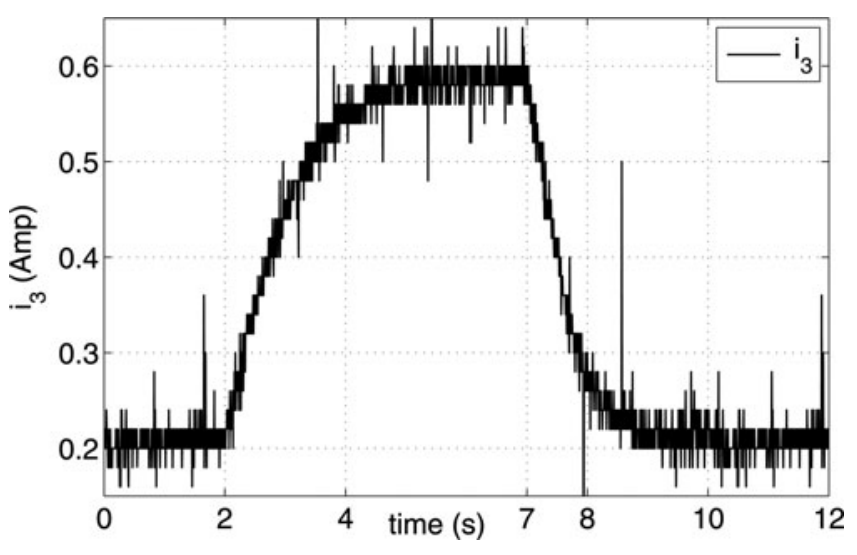

FIGURE 31. Current $i_{3}$ in the presence of constant load and output voltage reference steps.

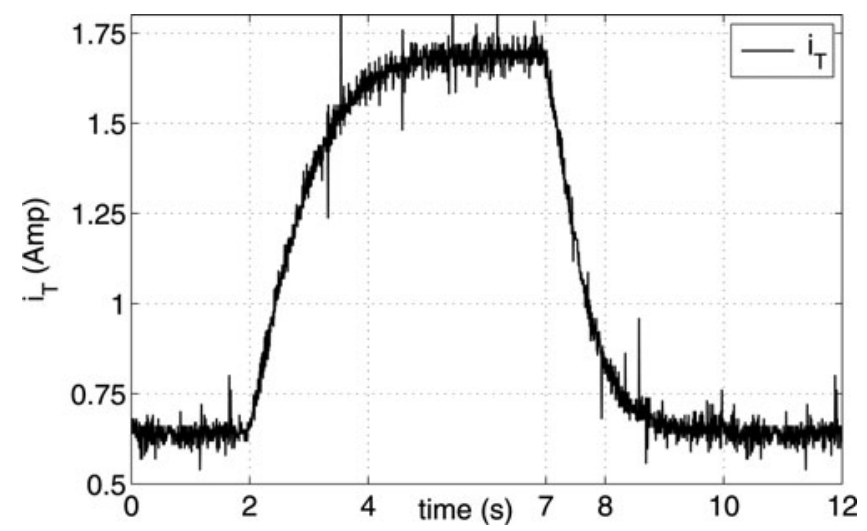

FIGURE 32. Total current $i_{T}$ in the presence of constant load and output voltage reference steps.

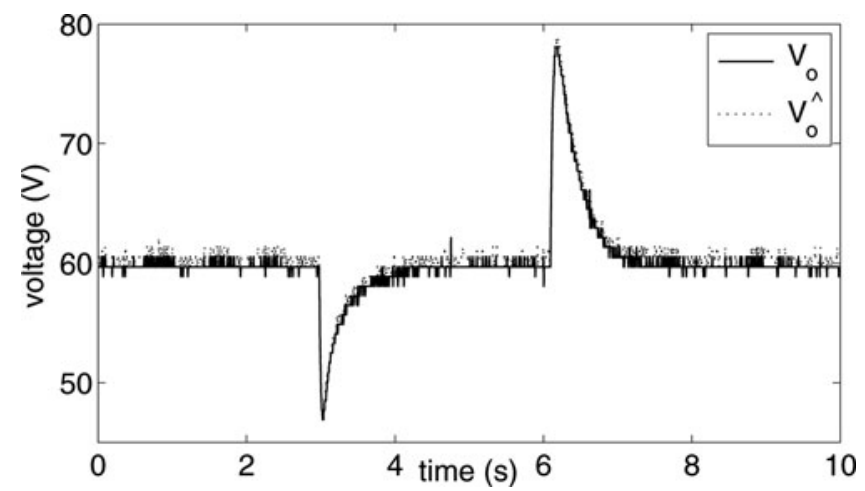

FIGURE 33. Output voltage $v_{o}$ and its estimate (provided by the observer) in the presence of load steps between 50 and 60 $\Omega$. Notice that the true output voltage perfectly converges to its reference value, presently set to $60 \mathrm{~V}$, despite the estimation error on $v_{o}$. The estimation quality is so accurate that the two curves are hardly distinguishable. 


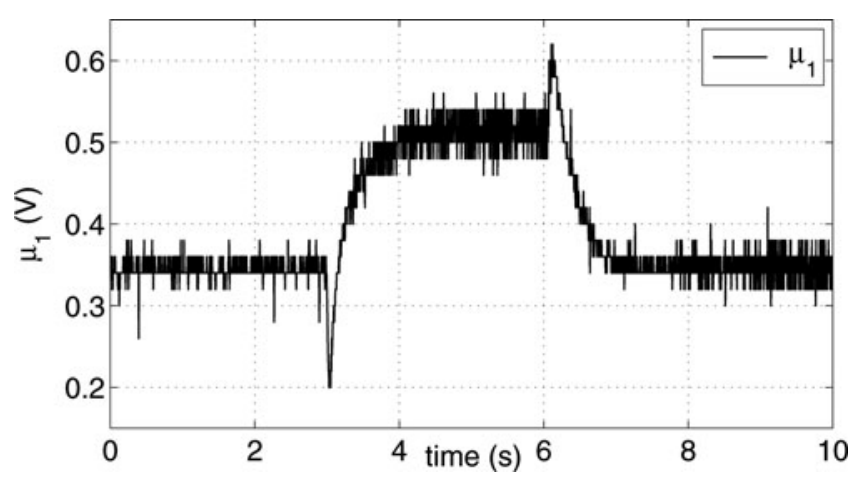

FIGURE 34. Duty cycle inputs $\mu_{1}$ in the presence of constant output reference voltage and load steps.

- output filtering capacitors $C=1200 \mu \mathrm{F}$ of aluminum electrolytic type and maximal voltage $400 \mathrm{~V}$; and

- a variable wound load resistance: $220 \Omega$ and $500 \mathrm{~W}$.

The experimental system components are recapitulated in Table 3. Again, the performances of the output feedback controller are illustrated considering two experimental protocols.

In the first protocol, the voltage reference is a step-like time-varying signal (stepping from 60 to $80 \mathrm{~V}$ and vice versa), while the resistance load is constant and adjusted to $100 \Omega$. The experimental system responses are shown by Figures 24 to 32 . Figure 24 confirms the good output voltage reference tracking as well as the good output voltage estimation. The corresponding control effort is illustrated by Figures 26 to 28 . It is seen that the control actions (i.e., duty ratios $\mu_{1}, \mu_{2}, \mu_{3}$ ) always remain quite within the allowed limits (i.e., the control limiter in Eq. (38) never saturates). Of course, one could get

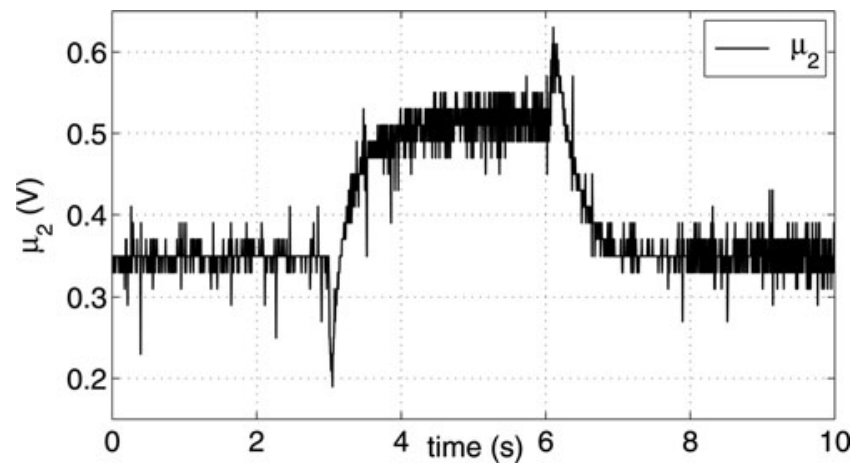

FIGURE 35. Duty-cycle inputs $\mu_{2}$ in the presence of constant output reference voltage and load steps.

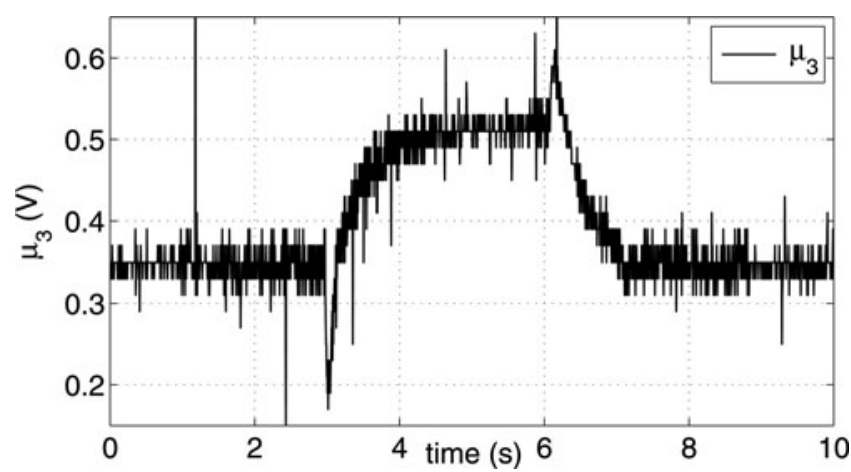

FIGURE 36. Duty-cycle inputs $\mu_{3}$ in the presence of constant output reference voltage and load steps.

a benefit of this feature to make the output voltage reference tracking a bit speedier by allowing the control action to saturate. Figures 29 to 32 confirm the good current sharing between branches.

In the second experimental protocol, the output voltage reference is kept constant, equal to $60 \mathrm{~V}$, whereas the load resistance is time varying, stepping from 60 to $50 \Omega$ and vice versa. Figure 33 confirms the good tracking quality of the controller, while Figures 34 to 36 show that this performance is achieved with a reasonable control effort. Indeed, it is seen that the duty ratios $\mu_{1}, \mu_{2}$, and $\mu_{3}$ remain quite beyond the allowed limits ( 0 and 1$)$. Obviously, one can take benefit from this feature and makes the output voltage reference in Figure 33 speedier after any load change. On the other hand, it is seen from Figures 37 to 40 that the total current is equally shared between all branches. Finally, Figure 41 shows that the resistance load is well estimated. In summary, the experimental results, described by Figures 24 to 41, clearly

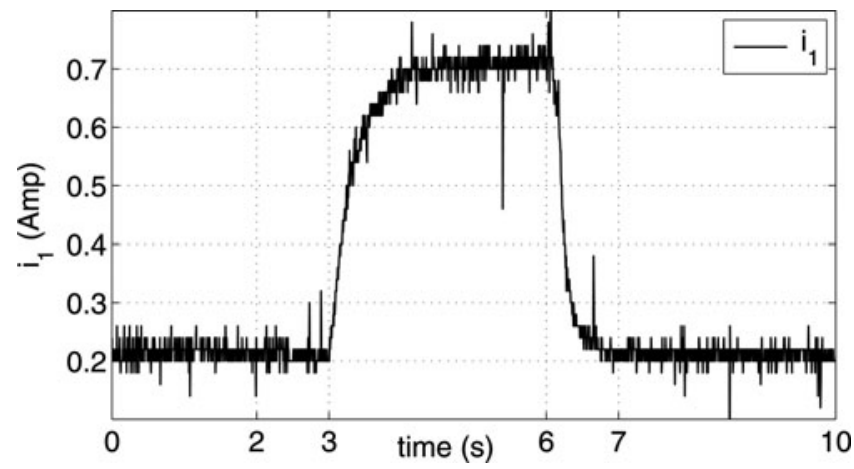

FIGURE 37. Current $i_{1}$ in the presence of constant output reference voltage and load steps. 


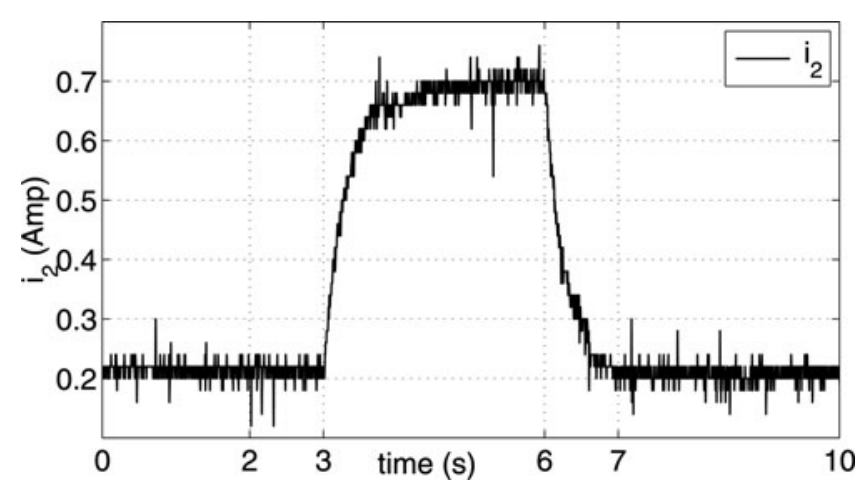

FIGURE 38. Current $i_{2}$ in the presence of constant output reference voltage and load steps.

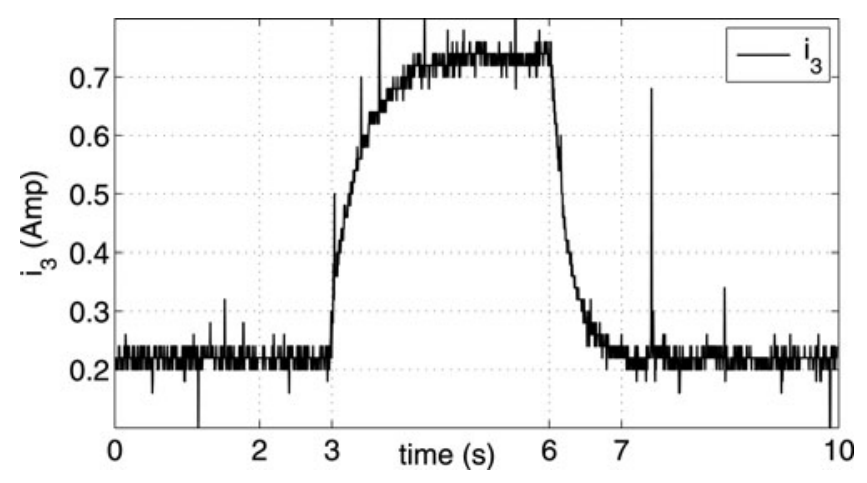

FIGURE 39. Current $i_{3}$ in the presence of constant output reference voltage and load steps.

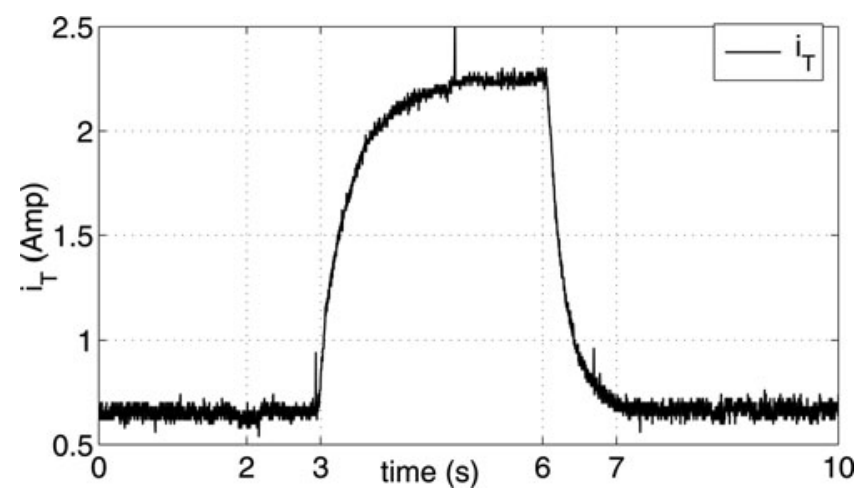

FIGURE 40. Total current $i_{T}$ in the presence of constant output reference voltage and load steps.

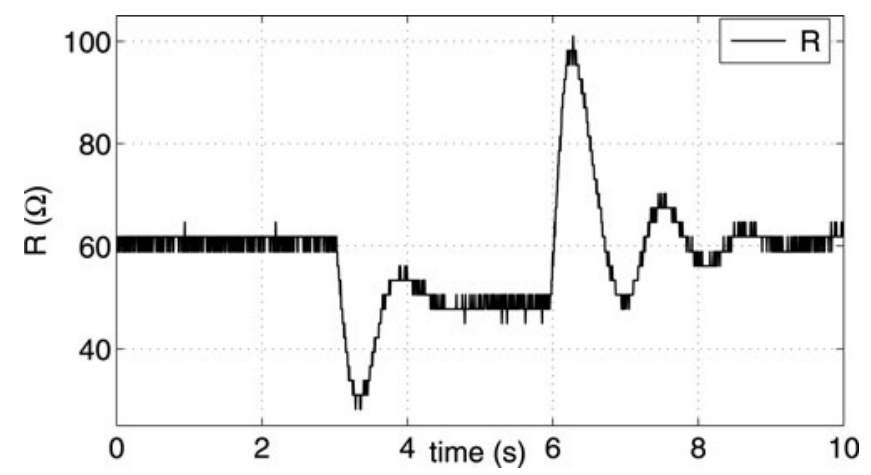

FIGURE 41. Resistance load estimate in the presence of load steps; the true load equals $60 \Omega$ on the interval [0,3 sec], it switches to $50 \Omega$ on $[3,6 \mathrm{sec}]$, and it again switches to $60 \Omega$ on $[7,10 \mathrm{sec}]$.

demonstrate that the output feedback controller meets its objectives.

\section{CONCLUSION}

This article has addressed the problem of controlling IBCs fed by FC generators. The problem is dealt with by designing an adaptive output feedback controller described by Table 1 . The controller includes state estimators providing online estimates of all currents in the interleaved paths, a parameter estimator providing online estimates of the unknown load resistance, and control laws generating the duty ratios for each path control switch. The formal analysis in Theorem 1 demonstrates that the proposed adaptive output feedback controller meets its objectives, i.e., perfect output voltage reference tracking and equal current sharing. This formal result is then confirmed both by simulation and experimental tests. It is also demonstrated that the controller tracks well the varying load resistance. As this is always the case in power converter control applications, the control limiter (Eqs. (32) and (33)) is inserted to protect the converter. This limiter is generally not accounted for in the analysis of the controller theoretical performances (as it increases the controller complexity). The extension of the analysis to account for that limitation represents an interesting research perspective of the present work.

\section{REFERENCES}

[1] Pukrushpan, J. T., Stefanopoulou, A. G., and Peng, H., Control of Fuel Cell Power Systems: Principles; Modeling; Analysis and Feedback Design, London: Springer-Verlag, 2004.

[2] Sharaf, O. Z., and Orhan, M. F., "An overview of fuel cell technology: Fundamentals and applications," Renew. Sustain. Energy Rev., Vol. 32, pp. 810-853, April 2014. 
[3] Boscaino, V., Miceli, R., Capponi, G., and Ricco Galluzzo, G., "A review of fuel cell based hybrid power supply architectures and algorithms for household appliances," Int. J. Hydrogen Energy, Vol. 39, No. 3, pp. 1195-1209, January 2014.

[4] Hoogers, G., Fuel Cell Technology Handbook, Boca Raton, Florida: CRC Press, 2003.

[5] Misoc, F., Morcos, M. M., and Lookadoo, J., "Effect of DCDC converter topologies and operation on the electrical performance of fuel cells," Electr. Power Compon. Syst., Vol. 38, No. 7, pp. 851-861, 2010.

[6] De Bernardinis, A., "Synthesis on power electronics for large fuel cells: From power conditioning to potentiodynamic analysis technique," Energy Convers. Manag., Vol. 84, pp. 174-185, August 2014.

[7] Zhang, M. T., Jovanovich, M. M., and Lee, F. C., "Analysis and evaluation of interleaving techniques in forward converters," IEEE Trans. Power Electr., Vol. 13, No. 4, pp. 690-698, July 1998.

[8] Shin, H. B., Park, J. G., Chung, S. K., Lee, H. W., and Lipo, T. A., "Generalized steady-state analysis of multiphase interleaved boost converter with coupled inductors," IEE Electr. Power Appl., Vol. 152, No. 3, pp. 584-594, 2005.

[9] Gyu-Yeong, C., Hyun-Soo, K., Byoung-Kuk, L., and WonYong, L., "Design consideration of interleaved converters for fuel cell applications," International Conference on Electronics, Machines, and Systems, Seoul, Korea, 8-11 October 2007.

[10] Newton, A., Green, T. C., and Andrew, D., "AC/DC power factor correction using interleaving boost and Cuk converters," IEEE Power Electronics and Variable Speed Drives Conference, pp. 293-298, London, UK, pp. 293-298, 18-19 September 2000.

[11] Veerachary, M., Senjyu, T., and Uezato, K., "Maximum power point tracking of coupled inductor interleaved boost converter supplied PV system," IEE Proc. Electr. Power. Appl., Vol. 150, No. 1, pp. 71-80, 2003.

[12] El Fadil, H., and Giri, F., "Robust nonlinear adaptive control of multiphase synchronous buck converters," Control Eng. Pract., Vol. 17, No. 11, pp. 1245-1254, 2009.

[13] El Fadil, H., Giri, F., and Guerrero, J. M., "Adaptive sliding mode control of interleaved parallel boost converter for fuel cell energy generation system," IMACS Trans. Math. Comput. Simulat., Vol. 91, pp. 193-210, 2013.

[14] Thounthong, P., Tricoli, P., and Davat, B., "Performance investigation of linear and nonlinear controls for a fuel cell/supercapacitor hybrid power plant," Int. J. Electr. Power Energy Syst., Vol. 54, pp. 454-464, January 2014.

[15] Sayed, K., Abdel-Salam, M., Ahmed, A., and Ahmed, M., "New high voltage gain dual-boost DC-DC converter for photovoltaic power systems," Electr. Power Compon. Syst., Vol. 40, No. 7, pp. 711-728, 2012.

[16] Kabalo. M., Paire, D., Blunier, B., Bouquain, D., Godoy Simões, M., and Miraoui, A., "Experimental evaluation of four-phase floating interleaved boost converter design and control for fuel cell applications," IET Power Electron., Vol. 6, No. 2, pp. 215-226, February 2013.

[17] Garcia, F. S., Pomilio, J. A., and Spiazzi, G., "Modeling and control design of the interleaved double dual boost converter," IEEE Trans. Ind. Electron., Vol. 60, No. 8, pp. 3283-3290, August 2013.
[18] Hegazy, O., Van Mierlo, J., and Lataire, P., "Analysis, modeling, and implementation of a multidevice interleaved DC/DC converter for fuel cell hybrid electric vehicles," IEEE Trans. Power Electron., Vol. 27, No. 11, pp. 4445-4458, November 2012.

[19] Subsingha, W., and Sarakarn, P., "4 phase interleaved dc boost converter for PEMFC applications," Procedia Eng., Vol. 32, pp. 1127-1134, 2012.

[20] Seyezhai, R., and Mathur, B. L., "Design and implementation of interleaved boost converter for fuel cell systems," Int. J. Hydrogen Energy, Vol. 37, No. 4, pp. 3897-3903, February 2012.

[21] Ahmed, N. A., "Computational modeling and polarization characteristics of proton exchange membrane fuel cell with evaluation of interface systems," European Power Electronics and Drives Journal, Vol. 18, No. 1, pp. 32-40, January 2008.

[22] Khalil, H., Nonlinear Systems, 3rd ed., Upper Saddle River, NJ: Prentice Hall, 2003.

[23] Muhammad, H. R., Power Electronics Handbook, 2nd ed., Pensacola, FL: Elsevier, 2007.

[24] Krein, P. T., Bentsman, J., Bass, R. M., and Lesieutre, B., "On the use of averaging for analysis of power electronic system," IEEE Trans. Power Electron., Vol. 5, No. 2, pp. 182-190, 1990.

[25] Sira-Ramirez, H. J., and Silva-Ortigoza, R., Control Design Techniques in Power Electronics Devices, London: Springer, 2006. 